\title{
Arctic Summer Airmass Transformation, Surface Inversions, and the Surface Energy Budget
}

\author{
Michael TJernström, ${ }^{\mathrm{a}, \mathrm{b}}$ MAtThew D. Shupe, ${ }^{\mathrm{c}, \mathrm{d}}$ IAN M. Brooks, ${ }^{\mathrm{e}}$ PegGy Achtert,,${ }^{\mathrm{e}}$ \\ JOHN PRYTHERCH, ${ }^{\mathrm{a}}$ AND JOSEPH SEDLAR ${ }^{\mathrm{a}, \mathrm{d}}$ \\ ${ }^{a}$ Department of Meteorology, and Bolin Centre for Climate Research, Stockholm \\ University, Stockholm, Sweden \\ ${ }^{\mathrm{b}}$ National Centre for Atmospheric Research, Mesoscale and Microscale \\ Laboratory, Boulder, Colorado \\ ${ }^{\mathrm{c}}$ NOAA/Earth System Research Laboratory, Boulder, Colorado \\ ${ }^{\mathrm{d}}$ Cooperative Institute for Research in the Environmental Sciences, University of \\ Colorado Boulder, Boulder, Colorado \\ e School of Earth and Environment, University of Leeds, Leeds, United Kingdom \\ ${ }^{\mathrm{f}}$ Department of Meteorology, University of Reading, Reading, United Kingdom
}

(Manuscript received 9 April 2018, in final form 23 October 2018)

\begin{abstract}
During the Arctic Clouds in Summer Experiment (ACSE) in summer 2014 a weeklong period of warm-air advection over melting sea ice, with the formation of a strong surface temperature inversion and dense fog, was observed. Based on an analysis of the surface energy budget, we formulated the hypothesis that, because of the airmass transformation, additional surface heating occurs during warm-air intrusions in a zone near the ice edge. To test this hypothesis, we explore all cases with surface inversions occurring during ACSE and then characterize the inversions in detail. We find that they always occur with advection from the south and are associated with subsidence. Analyzing only inversion cases over sea ice, we find two categories: one with increasing moisture in the inversion and one with constant or decreasing moisture with height. During surface inversions with increasing moisture with height, an extra $10-25 \mathrm{~W} \mathrm{~m}^{-2}$ of surface heating was observed, compared to cases without surface inversions; the surface turbulent heat flux was the largest single term. Cases with less moisture in the inversion were often cloud free and the extra solar radiation plus the turbulent surface heat flux caused by the inversion was roughly balanced by the loss of net longwave radiation.
\end{abstract}

\section{Introduction}

While the Arctic warms more than twice as fast as Earth on average (Blunden and Arndt 2017), there is no consensus on what mechanisms are most important for the Arctic amplification (Serreze and Francis 2006; Serreze and Barry 2011). There is, however, consensus that Arctic warming is attributable to global anthropogenic warming (e.g., Gillett et al. 2008; Koenigk et al. 2013) and that the concurrent rapid sea ice decline is a manifestation of this change (Min et al. 2008; IPCC 2013), while also contributing to the Arctic amplification.

Many different processes have been suggested as being responsible for the rapid Arctic warming. These can be divided into two groups: external forcing (in a regional context), which is mostly on a scale that should

Corresponding author: Michael Tjernström, michaelt@misu.su.se be resolved by models; and internal physical feedbacks, most of which are parameterized in models. Examples of the latter are often-interlinked processes related to clouds and aerosols (Kay and Gettelman 2009; Mauritsen et al. 2011; Liu and Key 2014), atmospheric boundary layer (ABL) processes (Bintanja et al. 2012; Pithan and Mauritsen 2014), and surface albedo (Perovich et al. 2007; Schröder et al. 2014; Fletcher et al. 2009). External forcings include changes in the meridional atmospheric transport of heat and/or moisture (Graversen et al. 2008, 2011; Kapsch et al. 2013; Cai and Tung 2012) and oceanic inflow of warmer water (Shimada et al. 2006; Polyakov et al. 2010). The Arctic climate results from the net balance between these two groups of processes: resolved/external and parameterized/internal. Energy is net imported from the south by the atmosphere (and to a lesser extent by the oceans), which regionally represents an external forcing, while internal feedback processes 
contribute to the radiative net loss of energy at the top of the atmosphere (TOA).

Since the advection of warm and moist air into the Arctic is resolved in models, studies of this aspect often use tools such as reanalysis products (e.g., Dee et al. 2011) and climate models (Woods et al. 2017). Such studies have been intensive over the last decade (e.g., Graversen et al. 2008, 2011; Kapsch et al. 2013, 2016; Woods et al. 2013; Pithan et al. 2014; Tjernström et al. 2015; Cox et al. 2016; Mortin et al. 2016; Cao et al. 2017; Naakka et al. 2018). Large positive anomalies in the summer sea ice melt have been linked to large positive anomalies in advection, especially in spring (Kapsch et al. 2013, 2014, 2016). Woods et al. (2013) argue that extreme large-scale advection events are responsible for a large part of the annually averaged energy transport, and correlate well with changes in Arctic surface temperature. Woods et al. (2017) also show that such events are poorly represented in global climate models. Studies of internal physical feedbacks, on the other hand, often involve subgrid processes that need to be parameterized in models, and hence more often use observations from field experiments or satellites. To the extent that models are used, they rely on parameterizations known to often work less than perfectly in the Arctic (e.g., Vihma et al. 2014).

We argue that this dichotomy in how to conceptualize the effect of these two groups of processes has served the Arctic poorly. Advection of warm and moist air into the Arctic is intimately coupled to internal physical processes, and those in turn affect the radiation balance at TOA (e.g., Morrison et al. 2012; Sedlar and Tjernström 2017). Some modeling studies have indicated such linkages. Pithan et al. (2014) used climate models to show how winter advection of warm air leads to the formation of mixed-phase stratocumulus, arguing that how this is handled in models has large effects on their nearsurface temperature climate. Kapsch et al. (2013) used ERA-Interim (Dee et al. 2011) while Cox et al. (2016) used radiation observations to statistically link negative anomalies in September sea ice extent to positive springtime anomalies in downwelling longwave radiation, presumably caused by positive anomalies in precipitable water and integrated cloud water due to enhanced atmospheric moisture transport. However, most studies have focused on the winter season and there have been very few experimental studies of such advection events (Perovich et al. 2002; Tjernström 2005; Persson 2012; Sedlar and Devasthale 2012; Tjernström et al. 2015; Sedlar and Tjernström 2017; Graham et al. 2017).

Here we utilize data from the 3-month-long Arctic Clouds in Summer Experiment (ACSE; Tjernström et al. 2015; Sotiropoulou et al. 2016), conducted during the Swedish-Russian-U.S. Arctic Ocean Investigation of Climate-Crysophere-Carbon Interactions (SWERUSC3; http://www.swerus-c3.geo.su.se) on board the Swedish research icebreaker Oden, to quantify the effects of summertime warm-air advection on melting sea ice. By chance, ACSE sampled a weeklong episode of warm-air advection northward from Siberia over melting multiyear sea ice in the eastern Siberian Sea. Analysis of the airmass transformation and its effects on the surface energy budget (Tjernström et al. 2015) led us to hypothesize the existence of a zone from the ice edge and in over the pack ice where warm-air advection in summer leads to enhanced surface heat flux. In this paper we extend the analysis to the entire ACSE dataset to explore this hypothesis further.

\section{Data and method}

\section{a. Arctic Clouds in Summer Experiment}

ACSE was a subprogram of the SWERUS-C3 expedition, with the objectives to study Arctic clouds and their interactions with ABL structure and the Arctic Ocean surface during the melt and early freeze-up seasons, along with influences of larger-scale atmospheric dynamics. It was conducted on the Swedish research icebreaker Oden in summer 2014, leaving Tromsö, Norway, on 5 July, following the Siberian Shelf while crossing the Kara, Laptev, East Siberian, and Chukchi Seas, arriving in Barrow, Alaska (now known as Utqiagivik), on 18 August. A second leg left Barrow on 21 August following a similar route back, albeit farther north, arriving in Tromsö on 5 October (Fig. 1). Sea ice (open water) conditions were encountered about $60 \%(40 \%)$ of the time, and while in sea ice, a range of conditions was encountered, from thick multiyear ice through broken melting ice to thin newly formed ice. Hence, although continuous ice-thickness measurements were not performed, the sea ice conditions spanned the expected range for late summer and early autumn

\section{b. Observations}

ACSE included an extensive suite of in situ and remote sensing instrumentation (Tjernström et al. 2015; Sotiropoulou et al. 2016), largely following the design from the Arctic Summer Cloud-Ocean Study (ASCOS; Tjernström et al. 2014), with the exception that no instruments were deployed on the ice during ACSE:

- Vertical atmospheric structure (temperature, humidity, and winds) was observed by 6-hourly radiosondes (Vaisala RS92); 341 profiles in total. 


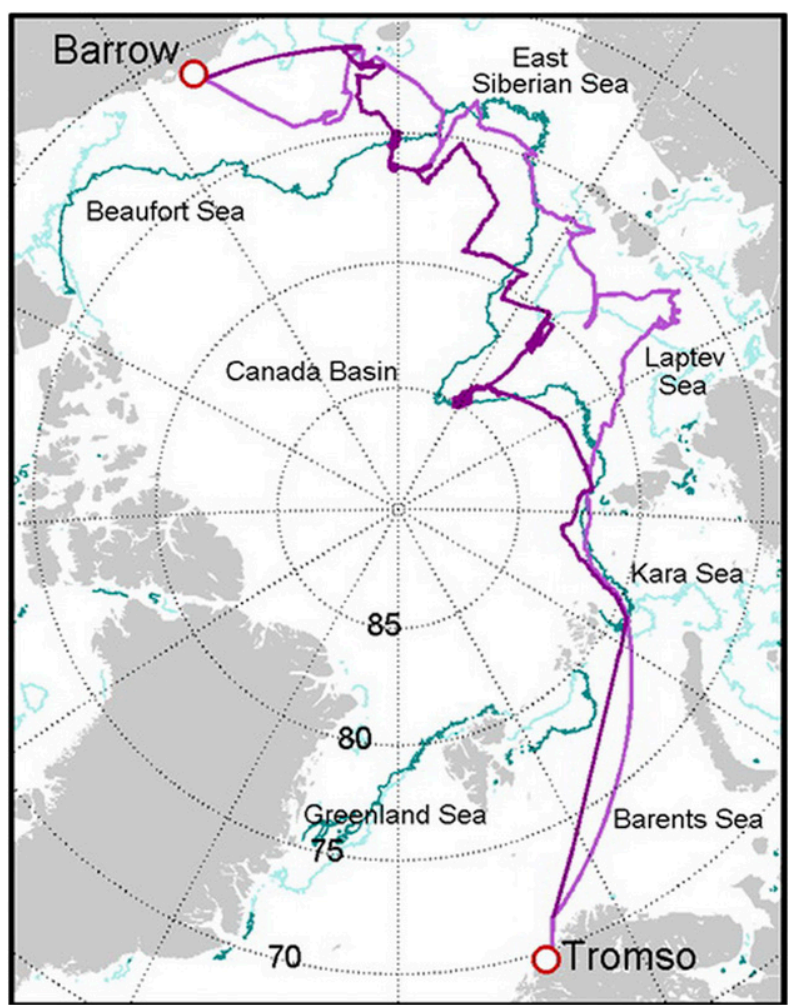

FIG. 1. Map of the Arctic Ocean showing the track of the icebreaker Oden for ACSE, the first, eastward leg and the second, westward leg in light and dark magenta, respectively. Light blue and dark green lines show the ice extent at the beginning and end of ACSE.

- Continuous, 5-min temperature and water vapor profiles were obtained from a Physics Humidity and Temperature Profiler (HATPRO) microwave radiometer, while integrated water vapor (IWV) and liquid water path (LWP) came from a physically constrained retrieval (Turner et al. 2007) using a Radiometrics MP-3000A radiometer.

- Continuous wind profiling was performed using a combination of a motion-stabilized scanning HALO Photonics Doppler lidar (Achtert et al. 2015) and 449$\mathrm{MHz}$ wind-profiling Doppler radar.

- Cloud properties were monitored with a vertically pointing, motion-stabilized 94-GHz Doppler cloud radar (Moran et al. 2012), with a first useful range gate at $127 \mathrm{~m}$ and a vertical resolution of $30 \mathrm{~m}$.

- The cloud radar was combined with measurements from the Doppler lidar, multiple Vaisala CL 51 ceilometers, and visibility observations from a Vaisala FD12P forward-scatter visibility sensor to determine cloud boundaries, cloud fraction, and fog occurrence.

- Surface temperature was measured with two independent, downward-looking infrared temperature sensors (Heitronics KT15-II) with a resolution of $0.03^{\circ} \mathrm{C}$ and absolute accuracy of $\pm 0.5^{\circ} \mathrm{C}$.
- Turbulent surface fluxes were measured by eddy covariance, using a heated Metek USA-1 sonic anemometer deployed $\sim 20 \mathrm{~m}$ above the surface on a mast at the bow of the ship, along with an XSens MTi-G-700 motion pack and a Licor LI-7500 open-path gas analyzer; Rotronic mean temperature and humidity sensors were also deployed nearby.

- A weather station $\sim 25 \mathrm{~m}$ above the sea surface measured standard meteorological variables: pressure, temperature, and relative humidity (RH) (Vaisala PTU300); wind speed and direction (heated Gill WindSonic M); and broadband downwelling short- and longwave radiation (Eppley PSP and PIR mounted on gimballed platforms).

One challenge with shipborne measurements is elimination of biases and random errors induced by the ship: its motion, especially the high-frequency motions caused by ice breaking or ocean waves, and flow distortion induced by ship itself. The cloud radar and the scanning lidar were installed on motion-stabilization platforms, minimizing the impact of ship motion; Doppler velocities were then corrected for the ship velocity and heading, for example, giving lidar winds in good agreement with radiosoundings [see Achtert et al. (2015) for details]. Wind measurements on the ship were corrected for the effects of flow distortion using the results of a computational fluid dynamics study of flow over Oden (Moat et al. 2015), while turbulence measurements were corrected for ship motions following Edson et al. (1998) and Prytherch et al. (2015).

Measuring upwelling surface radiation from a ship is logistically complicated and was not attempted. Upwelling longwave radiation was estimated from the Stefan-Boltzmann law with an assumed emissivity of unity, and measured surface temperature. A $1 \%-2 \%$ change in emissivity changes upwelling radiation well within the measurement uncertainty of the Eppley Precision Infrared Radiometer (PIR) used to measure downwelling longwave radiation.

Upwelling shortwave radiation was estimated using downwelling radiation and an assumed albedo; this is much more variable in reality and also uncertain. We use daily sea ice concentration from the Advanced Microwave Scanning Radiometer 2 (AMSR2) satellite passive microwave measurements (Spreen et al. 2008) from the grid cell for Oden's position at each observation, using the Artist sea ice algorithm (ASI 5), and scale the surface albedo assuming a constant albedo for the sea ice $(60 \%)$ and an $8 \%$ albedo for open water. This introduces uncertainty for two reasons. First, the assumed ice albedo does not take variability in melt ponds or snow characteristic into account; melt pond distribution was highly variable on a small scale, from 
$0 \%$ to over $80 \%$ over just a few kilometers. Second, the satellite sea ice concentration itself is also uncertain, particularly at a local scale. For the data analyzed here we determined that a $10 \%$ absolute error in albedo results in a $\sim 5 \%$ error in net surface solar radiation. We also note that we are comparing different groups of data, being less interested in the absolute values than in their differences. Hence, assuming this error to be random, we proceed with this method; the problem of the surface net solar radiation will be discussed further below.

\section{c. The case study}

In early August 2014, Oden navigated through multiyear sea ice extending south almost to the coast in the East Siberian Sea (Fig. 1). Over a week, warm continental air from Siberia flowed northward over this area of melting ice, with a surface temperature diabatically locked at $\sim 0^{\circ} \mathrm{C}$. As the lowest atmosphere adjusted, a strong surface inversion formed in which a dense fog developed (Tjernström et al. 2015).

While the warm-air advection lasted for over a week, conditions were far from homogeneous through the episode. Figure 2 shows time-height cross sections of temperature and moisture from radiosoundings and clouds from the cloud radar. A series of weak fronts passed until day of year (DoY) 213.0 (Fig. 2c), while the peak surface-inversion temperature and moisture remained constant at $\sim 10^{\circ} \mathrm{C}$ and $7-9 \mathrm{~g} \mathrm{~kg}^{-1}$, respectively (Figs. 2a,b). Visibility fluctuated below $1 \mathrm{~km}$, with occasionally higher values, while the lowest cloud base was mostly around $100 \mathrm{~m}$ (Fig. 2c). The inversion-top temperature and moisture then increased to $18^{\circ}-19^{\circ} \mathrm{C}$ and $\sim 11 \mathrm{~g} \mathrm{~kg}^{-1}$, respectively. Around DoY 216.0 another weak front passed while the inversion-top temperature and moisture remained high 1-2 days after. The highest temperature was $\sim 19^{\circ} \mathrm{C}$ at DoY $\sim 218.0$, and then started to decline; moisture also declined, starting somewhat later but more abruptly. After DoY $\sim 217.5$, fog/low clouds became sporadic and eventually dissipated.

The temperature inversion strength (Fig. 3a) varied, mostly between $10^{\circ}$ and $15^{\circ} \mathrm{C}$. The temperature gradient was at a maximum around $200 \mathrm{~m}$ but was smaller below $\sim 100 \mathrm{~m}$, indicating some surface-forced mixing; the inversion top was at $\sim 500 \mathrm{~m}$. The specific humidity inversion (Fig. 3b) had a similar shape up to $\sim 300 \mathrm{~m}$, with average inversion strength of $\sim 5 \mathrm{~g} \mathrm{~kg}^{-1}$. The equivalent potential temperature (Fig. 3c) had an inversion strength of $\sim 30^{\circ} \mathrm{C}$. The average wind speed profile (Fig. 3d) shows a low-level jet at $\sim 200 \mathrm{~m}$, with peak wind speeds of $10 \mathrm{~m} \mathrm{~s}^{-1}$ on average, reaching $\sim 16 \mathrm{~m} \mathrm{~s}^{-1}$.

Tjernström et al. (2015) concluded that the warm-airadvection episode resulted in a peak extra energy input
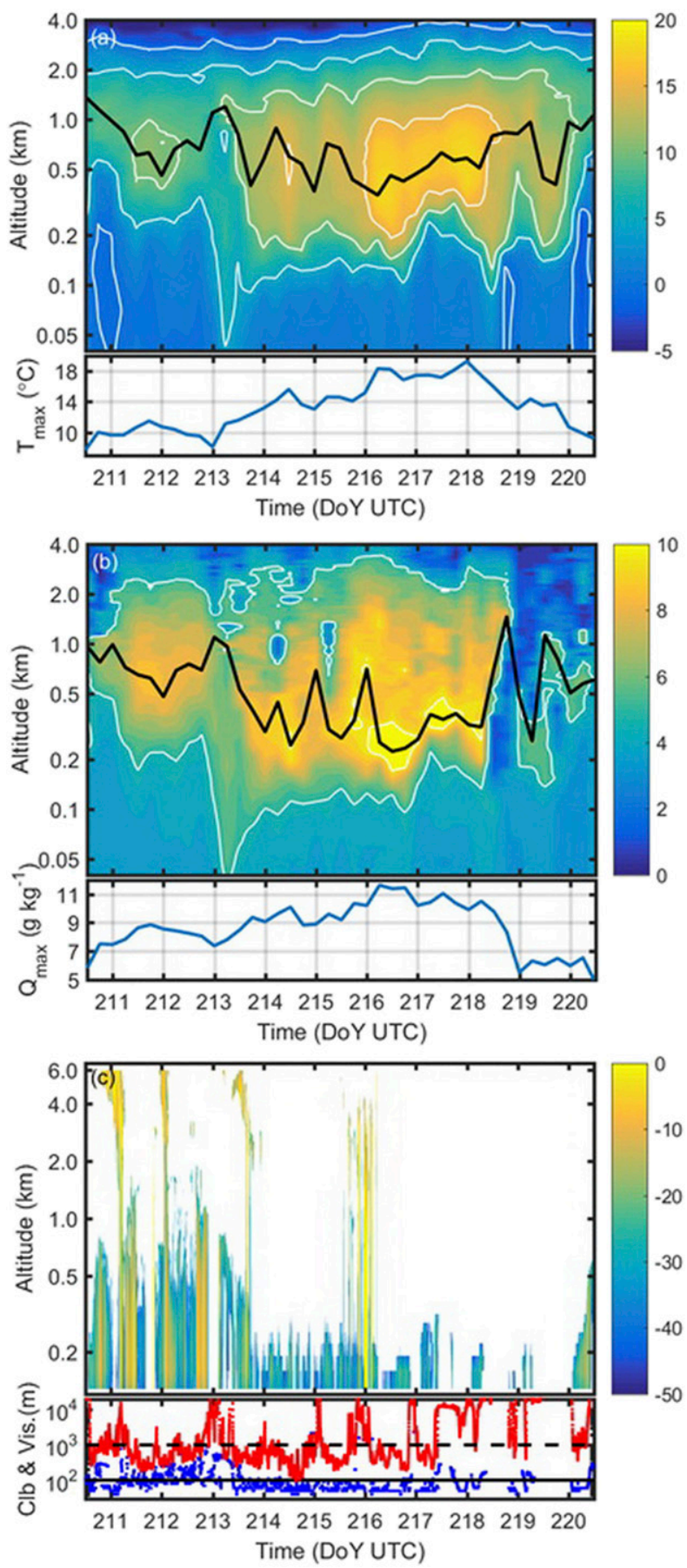

FIG. 2. Time-height cross sections for the case study discussed in the text of (a) temperature, with the time evolution of the inversion-top temperature below $\left({ }^{\circ} \mathrm{C}\right)$; (b) specific humidity, similarly with the maximum humidity $\left(\mathrm{g} \mathrm{kg}^{-1}\right)$; and (c) cloud radar reflectivity (dBZ), with the lowest cloud base (blue dots) and visibility (red dots) in meters below; note the logarithmic height scale. In (a) and (b) the black line indicates the height of the highest temperature and moisture. 

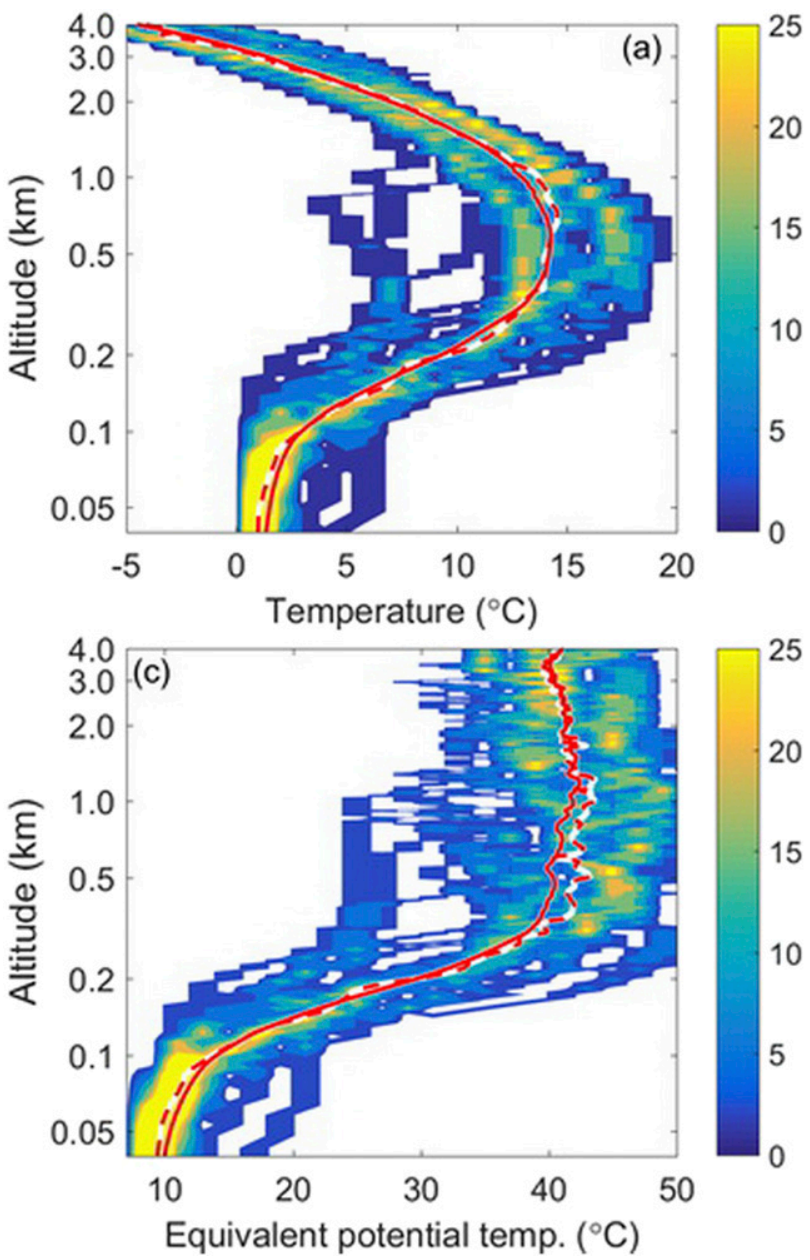
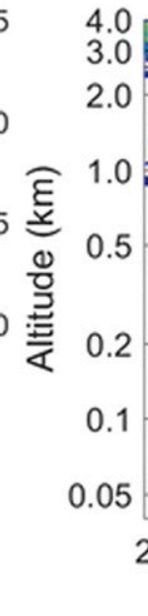

4.0

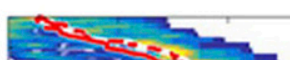

2.0

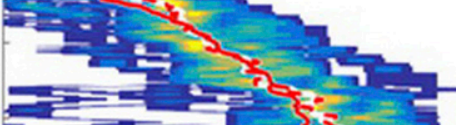

(b)

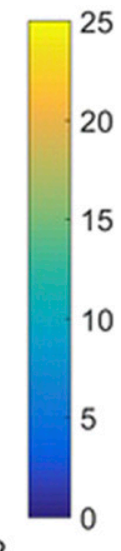

0.05

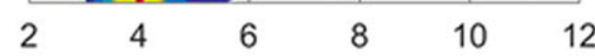

Specific humidity $\left(\mathrm{g} \mathrm{kg}^{-1}\right)$

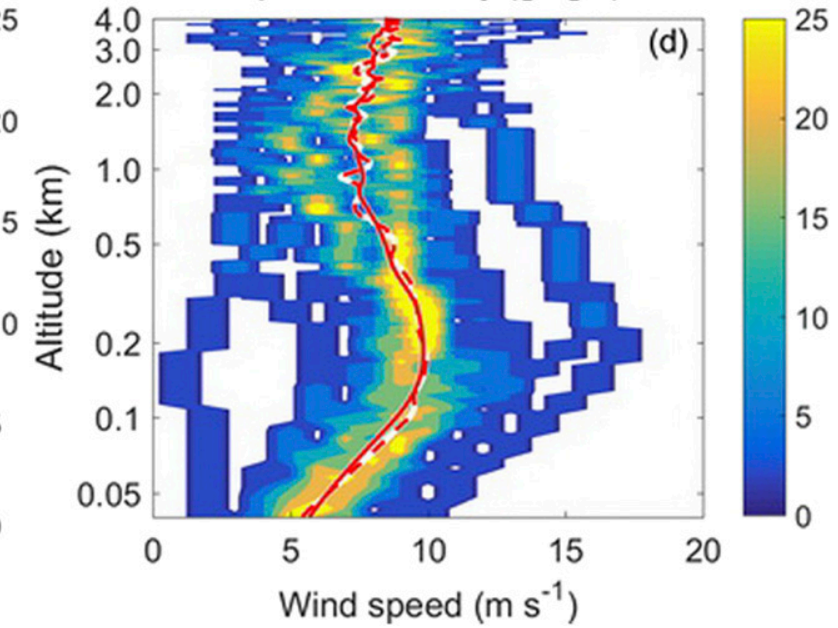

FIG. 3. The probability of (a) temperature $\left({ }^{\circ} \mathrm{C}\right)$, (b) specific humidity $\left(\mathrm{g} \mathrm{kg}^{-1}\right)$, (c) equivalent potential temperature $\left({ }^{\circ} \mathrm{C}\right)$, and $(\mathrm{d})$ wind speed $\left(\mathrm{m} \mathrm{s}^{-1}\right)$ as a function of height from the entire case study, based on 28 profiles (4 profiles per day for 7 days). Note that the probability is here defined so that the cumulative probability is $100 \%$ for each height; see the text for a discussion. Red solid and dashed lines indicate mean and median profiles, respectively.

to the surface of about $30-40 \mathrm{~W} \mathrm{~m}^{-2}$. This resulted from positive surface net longwave radiation during DoY 211-217 and a downward surface turbulent heat flux, which was largest during DoY 216-220. Both are direct consequences of the airmass transformation when warm and moist air encounters a surface temperature nearly constant at $0^{\circ} \mathrm{C}$. This promotes the stable near-surface inversion, while the cooling leads to fog formation. Solar radiation was attenuated by fog, but net solar radiation was modest and its decrease, most significant during the first half of the period, was more than balanced by the large surface net longwave radiation and turbulent heat fluxes.

Using satellite data, Sedlar and Tjernström (2017) subsequently showed that this event had a substantial impact on the outgoing longwave radiation (OLR) at TOA; increasing it by about $20 \mathrm{~W} \mathrm{~m}^{-2}$. They also showed that similar events occur sufficiently often in summer to generate a monthly averaged TOA OLR anomaly of $2-4 \mathrm{~W} \mathrm{~m}^{-2}$, and that the corresponding atmospheric cooling is sufficient to impact the atmospheric circulation.

\section{d. The hypothesis}

Over a decade of research supported by field measurements (e.g., Uttal et al. 2002; Leck et al. 2001; Tjernström et al. 2004, 2014) has inspired the formulation of a conceptual model of low clouds over the central Arctic Ocean, north of $80^{\circ} \mathrm{N}$ [Morrison et al. 2012; Sedlar et al. 2011, 2012; Shupe et al. 2006, 2013; Brooks et al. 2017; see Tjernström et al. (2012) for a review]. The cloud fraction is usually high and clouds are often mixed-phase stratocumulus; a thin, widespread and persistent layer of supercooled-liquid 


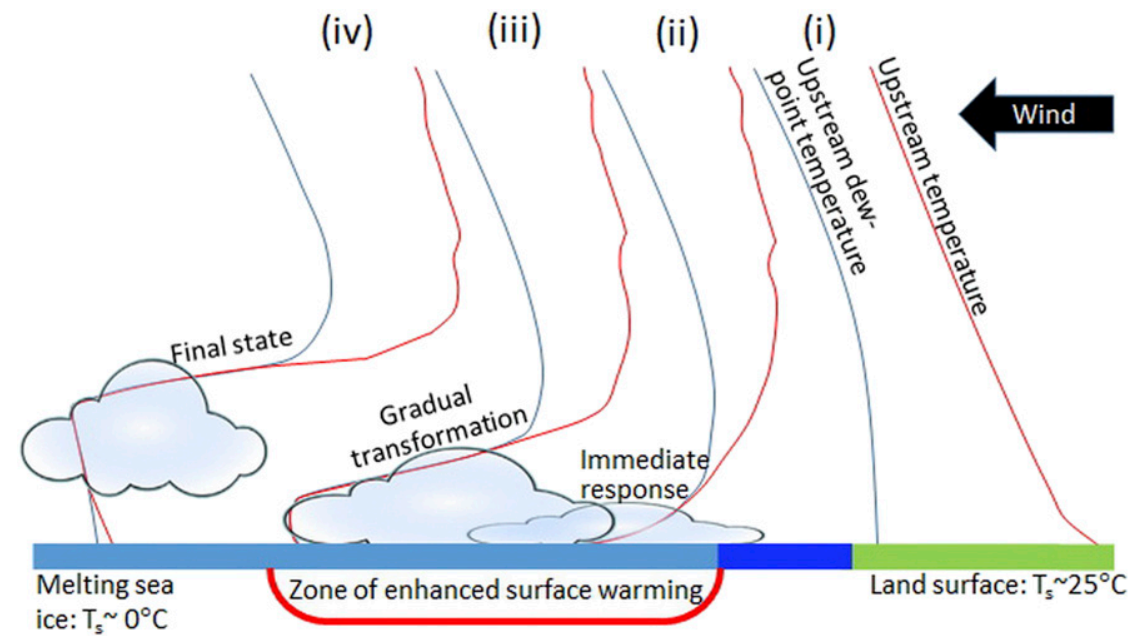

FIG. 4. Schematic of the proposed hypothesis showing the temperature and dewpoint profiles of the advected air, from right (i) to left (iv) as the air propagates from land (green), over ocean (dark blue), to melting sea ice (light blue); see the text for a discussion.

precipitating ice particles (e.g., Shupe et al. 2006, 2011). While the liquid layer remains optically thick, the cloud top cools efficiently to space, generating vertical mixing by negative buoyancy, resulting in a well-mixed layer below a cloud-top inversion (Shupe et al. 2013). This layer often extends below the cloud base, sometimes to the surface (e.g., Brooks et al. 2017). Transitions are abrupt, as frontal systems bring new air masses, but although clouds may vary in depth, height, and detail, the structure largely remains unchanged (Morrison et al. 2012). The effect of the clouds, compared to cloud-free conditions, is often a surface warming, with a critical effect on the seasonal extent of the summer sea ice melt (Intrieri et al. 2002; Shupe and Intrieri 2004; Sedlar et al. 2011; Kapsch et al. 2013, 2016).

The ABL and cloud characteristics from ACSE (Sotiropoulou et al. 2016; Tjernström et al. 2015) are in stark contrast to this conceptual model. The cloudy ABL was often stably stratified, not well mixed, and the temperature of the clouds was often well above freezing, hence, no cloud ice. During the episode described above, clouds were warmer than the surface. Hence, the enhanced surface net longwave radiation in combination with the downward turbulent heat (sensible plus latent) flux led to additional heat flux into the surface compared to the prototypical cloud-capped well-mixed ABL. Clearly, the proximity of the ice edge and advection of warm air are key to understanding this situation. These observations led us to formulate the following hypothesis:

As warm air from the south flows in over melting sea ice, the near-surface air temperature must adjust to the surface temperature of the melting sea ice; this leads to the formation of a surface temperature inversion and fog/low clouds. Farther downstream the ABL gradually cools and mixing, both from cloud-top buoyancy and surface roughness, eventually transforms the $A B L$ to the near-adiabatic cloud-capped $A B L$ characteristic of the central Arctic Ocean. In a zone downwind of the ice edge, where surfaceinversion and fog conditions dominate, the surface is exposed to an additional heat flux as a result of the airmass transformation.

The hypothesis is illustrated in Fig. 4. As the warm air to the right (i) is advected over the ice edge, the immediate response to the $0^{\circ} \mathrm{C}$ surface is formation of a sharp surface inversion and a shallow fog (ii); with the large near-surface temperature reduction, even modest upstream relative humidity will lead to supersaturation. As mechanical surface mixing and cloud-top buoyant mixing acts on this system, the ABL gradually becomes more well mixed and the fog deepens (iii), the wellmixed layer deepens, the cloud lifts from the surface and the $\mathrm{ABL}$ transforms to the often-observed persistent well-mixed cloud-capped ABL (iv), typically extending from a few hundred meters to $\sim 1 \mathrm{~km}$ above the surface (Sedlar 2014; Sotiropoulou et al. 2014; Brooks et al. 2017).

Note that, contingent on surface albedo and solar zenith angle (e.g., Shupe and Intrieri 2004; Sedlar et al. 2011), the presence of Arctic stratocumulus often leads to a surface heating compared to cloud-free conditions. The tenet of this hypothesis is that there is a zone inside the ice edge where this heating effect is enhanced, due to the combination of a warm high-emissivity fog and the downward turbulent heat flux, both resulting from the 
surface inversion. In contrast, in the well-mixed case the cloud base is always cooler than the surface while the turbulent heat fluxes are small (e.g., Tjernström et al. 2012).

A full observation-based test of this hypothesis would require measurements along an airmass trajectory; hence, with our single-point observations we can only test the first parts of the hypothesis: that warm-air advection over melting sea ice consistently leads to formation of a strong surface inversion with dense fog and that this leads to an additional energy flux to the surface. The rest of this paper is thus devoted to examining these parts of this hypothesis.

\section{e. Inversion detection}

Rather than studying individual cases, we perform this analysis in a statistical framework based on a few key parameters. The two key features of the discussion above are the starting point for the analysis: (i) the surface inversion over (ii) melting sea ice. To detect surface inversions with high temporal resolution, we use 5-min-resolution temperature and moisture profiles from the HATPRO microwave radiometer, bias corrected through extensive comparisons with 6-hourly radiosondes.

We select all profiles featuring a surface inversion by first identifying the profile's highest temperature $T_{i}$ below $3 \mathrm{~km}$ and its height $z_{i}$, and then requiring that $T_{i}>$ $T(z)>T_{0}$ for $z<z_{i}$ ( $T_{0}$ is surface temperature). We follow the same procedure for the moisture inversions, finding $Q_{i}$ and $z_{i q}$. The depth of surface inversions in temperature and moisture need not be the same. Also $z_{i q}$ and $\Delta Q\left(=Q_{i}-Q_{0}\right)$ are set to zero if moisture decreases with height, even when there is a temperature inversion.

\section{Results}

\section{a. Inversion characteristics}

Figures $5 \mathrm{a}$ and $5 \mathrm{~b}$ shows the statistics of all identified temperature and moisture inversions. Temperature inversion strengths, $\Delta T\left(=T_{i}-T_{0}\right)$, span $0^{\circ}-20^{\circ} \mathrm{C}$, with most cases in the $2^{\circ}-10^{\circ} \mathrm{C}$ interval. Correspondingly, $\Delta Q$ spans $0-9 \mathrm{~g} \mathrm{~kg}^{-1}$, most commonly $\Delta Q=0-2 \mathrm{~g} \mathrm{~kg}^{-1}$; the high percentage for $\Delta Q=0$ is because not all temperature inversions feature a moisture inversion. Both temperature and moisture inversions are mostly 200 $800 \mathrm{~m}$ deep; a few temperature inversions are $>1 \mathrm{~km}$ deep and $>10 \%$ of all moisture inversions are either very shallow or nonexistent given the definitions used. Based on this result, we further subdivide the surface inversions into two categories:
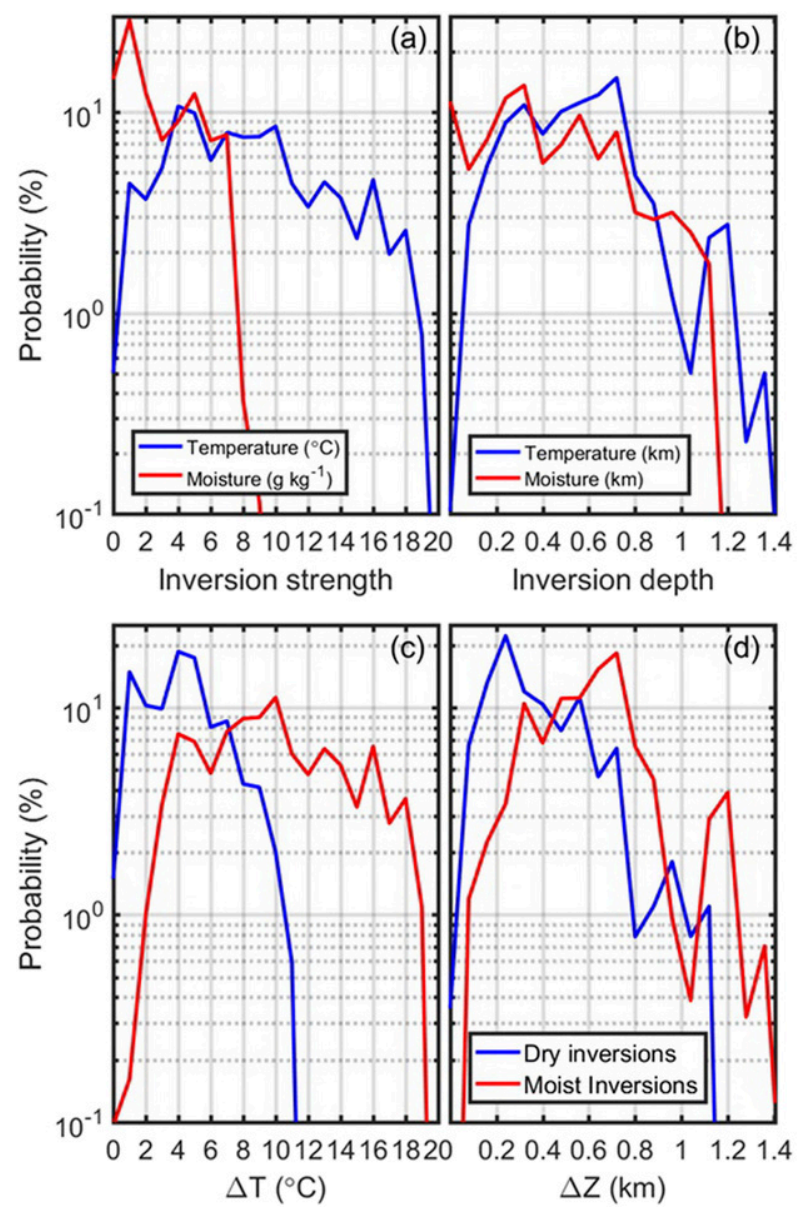

FIG. 5. Probability distributions for (a) the strength $\left({ }^{\circ} \mathrm{C}\right.$ and $\left.\mathrm{g} \mathrm{kg}^{-1}\right)$ and (b) the depth $(\mathrm{km})$ of the temperature and moisture inversions, and $(\mathrm{c})$ the strength $\left({ }^{\circ} \mathrm{C}\right)$ and $(\mathrm{d})$ the depth $(\mathrm{km})$ of the DSI (dry) and MSI (moist) temperature inversions. See the text for definitions.

1) Dry surface inversions (DSI): surface temperature inversions where $\Delta Q<1 \mathrm{~g} \mathrm{~kg}^{-1}$;

2) Moist surface inversions (MSI): surface temperature inversions with $\Delta Q>1 \mathrm{~g} \mathrm{~kg}^{-1}$.

The threshold $\Delta Q$ value is a compromise, partly determined from the peak probability in Fig. 5a, and partly to ensure a reasonable amount of data in both DSI and MSI categories. Using $\Delta Q=0$ would limit the number of DSI cases, making a statistical analysis difficult. Figures $5 \mathrm{c}$ and $5 \mathrm{~d}$ show the statistics of DSIs and MSIs separately. MSIs are significantly stronger and somewhat deeper than DSIs. The exact statistics are sensitive to the threshold $\Delta Q$ value but the structural differences, with MSIs being deeper and stronger, are robust. Note also that there is a potential joint dependence between $\Delta T$ and $\Delta Q$. A large $\Delta Q$ requires large $\Delta T$, because of the saturation humidity dependence on temperature; the opposite need not be true. 

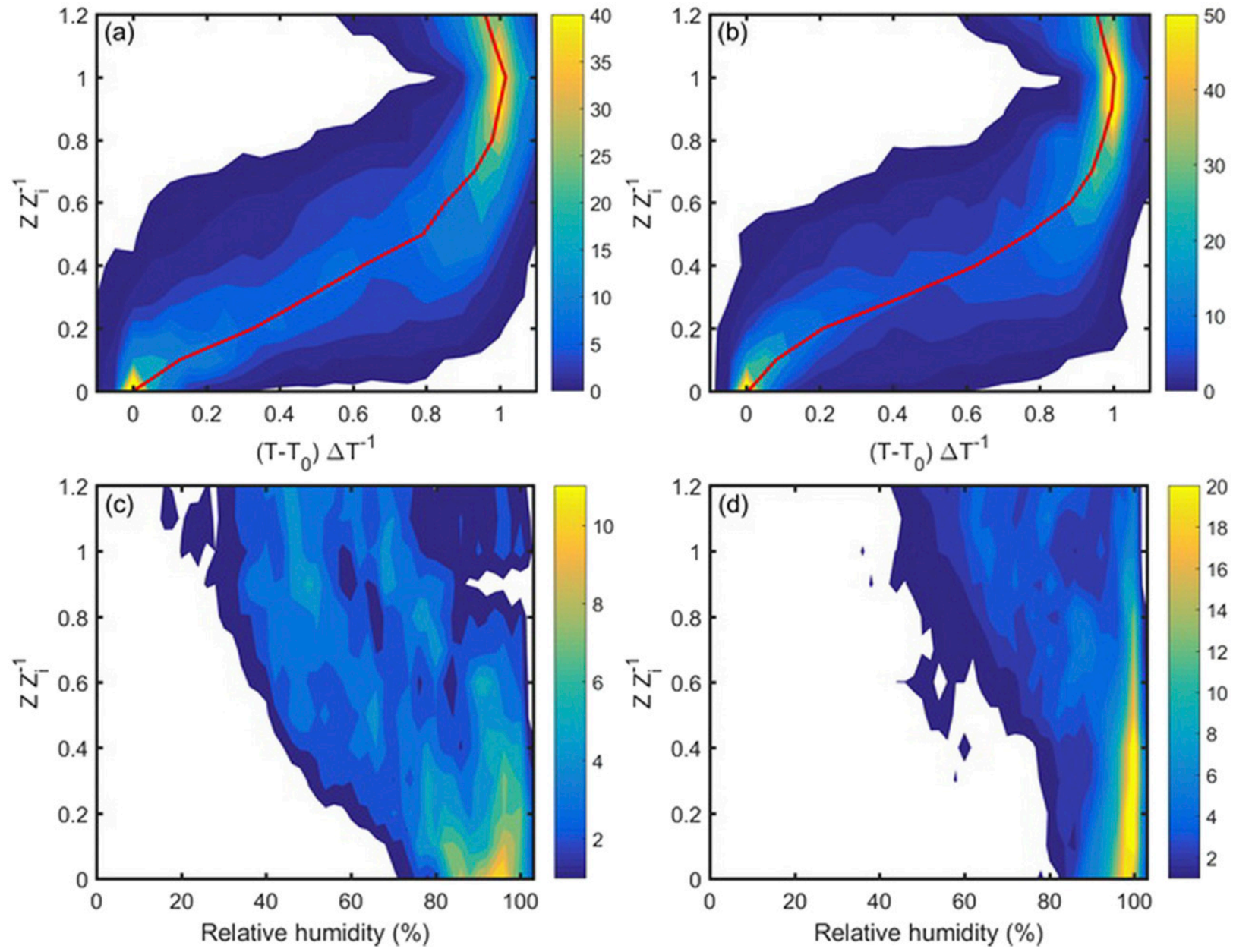

FIG. 6. Normalized probability profiles of (top) temperature for (a) DSI and (b) MSI and (bottom) relative humidity for (c) DSI and (d) MSI. The height scale is normalized to unity at the inversion top and for temperature the $x$ axis is normalized by the temperature jump across the inversion. The red solid line in (a) and (b) is the median profile.

Figure 6 shows the probability distributions of all DSI and MSI temperature and moisture profiles. All heights are normalized to the temperature inversion depth, while temperature is normalized by the inversion strength. The mean normalized temperature inversion displays a weakly S-shaped form, indicating the effects of nearsurface mixing with a constant surface temperature, in contrast to an inversion resulting from ongoing surface cooling, as with radiation inversions. For both DSI and MSI, the relative humidity is high near the surface; more so for MSI than for DSI. However, even for MSIs, high relative humidity tapers off with height and in many cases the relative humidity starts to decline around $z z_{i}^{-1}=0.5-0.8$. For DSIs relative humidity $<80 \%$ is more common in the upper half of the temperature inversion.

For completeness, Fig. 7 shows similar statistics for temperature profiles classified as not having a surface inversion [i.e., no surface inversion (NSI)]. Figure 7a's data are normalized similarly to Figs. $6 a$ and $6 \mathrm{~b}$, but scaling altitude with the ABL depth, using the height to the base of the strongest elevated inversion below $3 \mathrm{~km}$. This reveals a near-linear temperature decrease across the ABL as expected in a well-mixed ABL. Figure $7 \mathrm{~b}$ shows the absolute probability of the temperature decrease across the ABL as a function of ABL depth, generally indicating shallow near-adiabatic temperature profiles.

Figure 8 shows the daily fractional occurrence of all surface temperature inversions and of only MSIs, across the entire expedition; the local sea ice concentration is indicated below. Many of the surface-inversion days, especially for MSIs, relate to the episode described in section $2 \mathrm{a}$ embedded in the DoY $=208-228$ time frame; however, surface inversions are distributed over most of the expedition.

Determining for what larger-scale meteorological conditions inversions occur is difficult, since Oden semicontinuously traversed a considerable east-west distance 

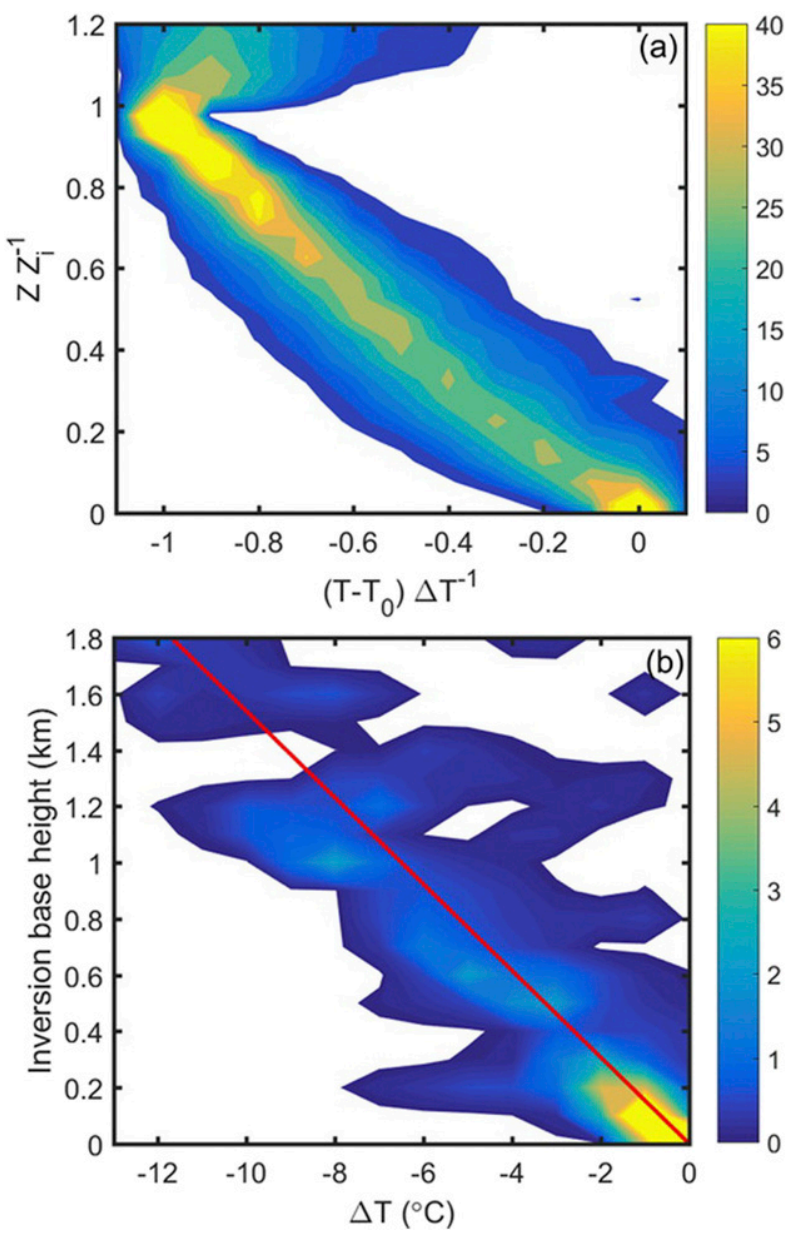

FIG. 7. Probability of (a) normalized temperature for all the NSI cases as a function of height normalized using the ABL depth defined as the height to the inversion base and (b) the temperature jump across the ABL as a function of the actual ABL depth. The red line in (b) is the $0.0065 \mathrm{~K} \mathrm{~m}^{-1}$ lapse rate, approximating the moist adiabat.

on a complicated track roughly parallel to the Siberian coastline (Fig. 1) while under the influence of different synoptic settings. Figures 9 and 10 show results from daily back trajectories, calculated with receptor points at Oden's location at three altitudes: $0.5,1$, and $3 \mathrm{~km}$. All the trajectories were calculated using HYSPLIT (Stein et al. 2015) with three-dimensional winds from the NCEP reanalysis. Figures $9 a-c$ explores the meridional location of the approaching air relative to the receptor latitude of Oden at $0.5 \mathrm{~km}$. When surface inversions are present (Figs. 9b,c), the air on average has an origin $3^{\circ}-4^{\circ}(330-440 \mathrm{~km})$ south of Oden $\sim 1.5$ days earlier, somewhat farther south for MSIs. For NSIs, there is no such average tendency, although the scatter is large. Figure $9 \mathrm{~d}$ shows that this behavior is consistent through the lower atmosphere, except for the highest receptor altitude $(3 \mathrm{~km})$ for DSIs.

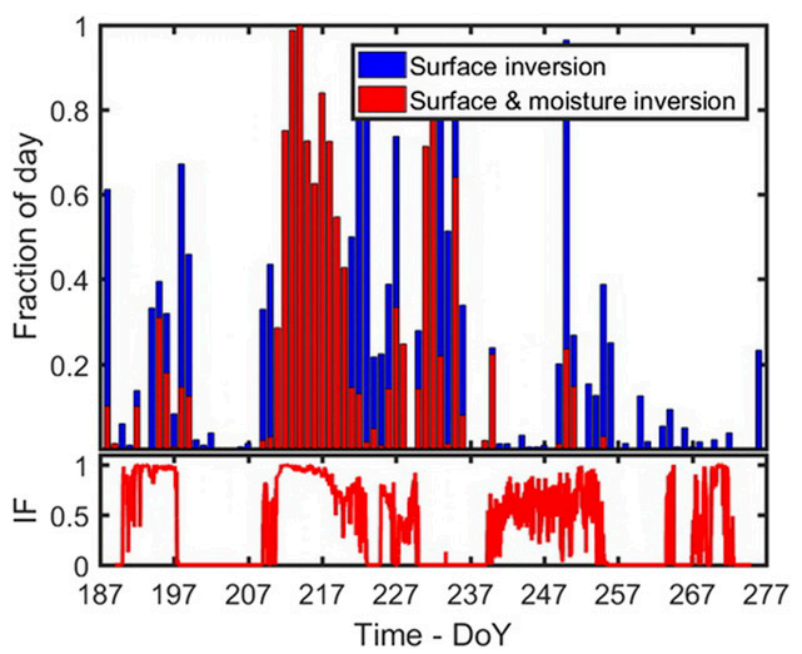

FIG. 8. (top) The daily frequency of all (blue) and moist (red) inversions and (bottom) the AMSR2 sea ice concentration interpolated to the location of Oden across the entire field campaign.

Figure 10 similarly illustrates the vertical path of these back trajectories; Figs. 10a-c show the results for the 500-m receptor height, and Fig. 10d shows the relative vertical displacement for all receptor heights. For inversion cases, there is consistent subsidence during the 1.5-2 days prior to reaching Oden's location. For DSIs, median subsidence is $0.3-0.4 \mathrm{~cm} \mathrm{~s}^{-1}$ over $\sim 36 \mathrm{~h}$, while for MSIs subsidence is weaker but occurring over a longer time. For NSIs there are no systematic vertical motions.

These results indicate that surface inversions during ACSE occurred predominantly when the air had a trajectory from the south, confirming one part of the hypothesis, and that the flow is likely associated with high pressure conditions, as indicated by the subsidence. Note that the case study in section 2a occurred on the western flank of a blocking anticyclone (Tjernström et al. 2015).

From here on, we restrict the analysis to cases when Oden was in sea ice, defining this as sea ice concentrations (SIC) $>15 \%$, assuming this is sufficient to control the surface temperature when the ice is melting or freezing. This amounts to $51 \%$ of all ACSE data; NSI is $67 \%$, DSI is $12 \%$, and MSI is $21 \%$ of all cases in ice, corresponding to 7301,1338 , and 2247 five-min samples, respectively.

In the discussion that follows all data was averaged (or in the case of the 20-min turbulent fluxes, interpolated) to the same 5-min observation intervals as for the microwave radiometer. We will present the results as probability density functions (PDF) for different variables comparing NSI, DSI, and MSI classes.

\section{b. Integral measures of water vapor and cloud water}

Figures 11a and 11b show PDFs of IWV and LWP for the three inversion categories. While the IWV PDFs for 

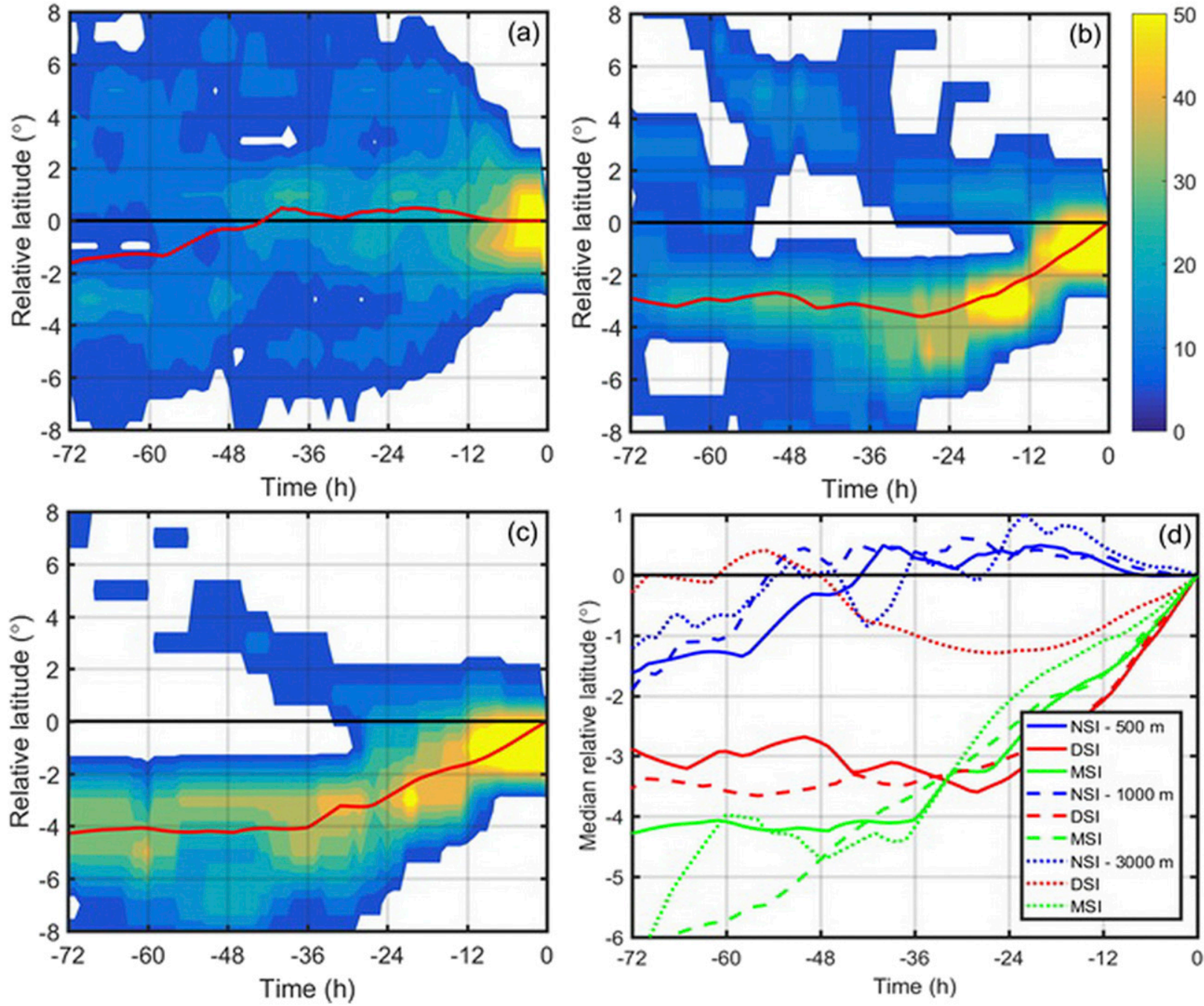

FIG. 9. The relative meridional displacement for air approaching Oden as a function of time, from back trajectories with receptor points at Oden's locations (a)-(c) $500 \mathrm{~m}$ above the surface for (a) NSI, (b) DSI, and (c) MSI; the solid red line shows the median trajectory. (d) The median latitude displacement for all three cases at three different heights is shown; see legend.

DSIs and NSIs are similar in shape, the PDF for MSIs is substantially higher. While the MSI PDF is also bimodal, its median value is higher by over a factor of 2 . Hence, the troposphere is significantly moister for MSIs, consistent with advection of warm, moist air.

Results for LWP (Fig. 11b) are more complex. First, all three PDFs show nonzero probability for LWP $<0$, which reflects the uncertainty in this type of retrieval: $\pm 0.02 \mathrm{~kg} \mathrm{~m}^{-2}$ (Westwater et al. 2001). Second, this instrument senses all cloud liquid in the atmospheric column, not just ABL clouds. High values can therefore result from deeper cloud systems. However, since these occupy a small fraction of time this should only contribute to low probabilities for the highest values; LWP $>0.2 \mathrm{~kg} \mathrm{~m}^{-2}$. The median LWP for MSIs is $40 \%$ higher than for NSIs, while DSIs have a median of
$0 \mathrm{~kg} \mathrm{~m}^{-2}$. MSIs have the largest probabilities for LWP $>$ $0.1 \mathrm{~kg} \mathrm{~m}^{-2}$, while NSIs dominate for $0.02<$ LWP $<$ $0.1 \mathrm{~kg} \mathrm{~m}^{-2}$ and DSIs dominate for the smallest LWPs.

We interpret this as follows: during DSIs there is less cloud cover than for both NSIs and MSIs; the zero median value indicates that DSIs are cloud free about half the time, and the low probabilities for LWP > $0.1 \mathrm{~kg} \mathrm{~m}^{-2}$ indicate that when clouds are present they are often optically thin. For NSIs and MSIs, cloud-free conditions are less frequent $(\sim 20 \%)$. MSIs more frequently occur with denser clouds (high LWP). Examining the cumulative probabilities (not shown) MSIs have LWP $>0.15 \mathrm{~kg} \mathrm{~m}^{-2}$ about $25 \%$ of the time, compared to only $10 \%$ for NSIs.

As another indicator of ABL moisture, Fig. 11c shows PDFs of visibility. Note that the upper limit for this 

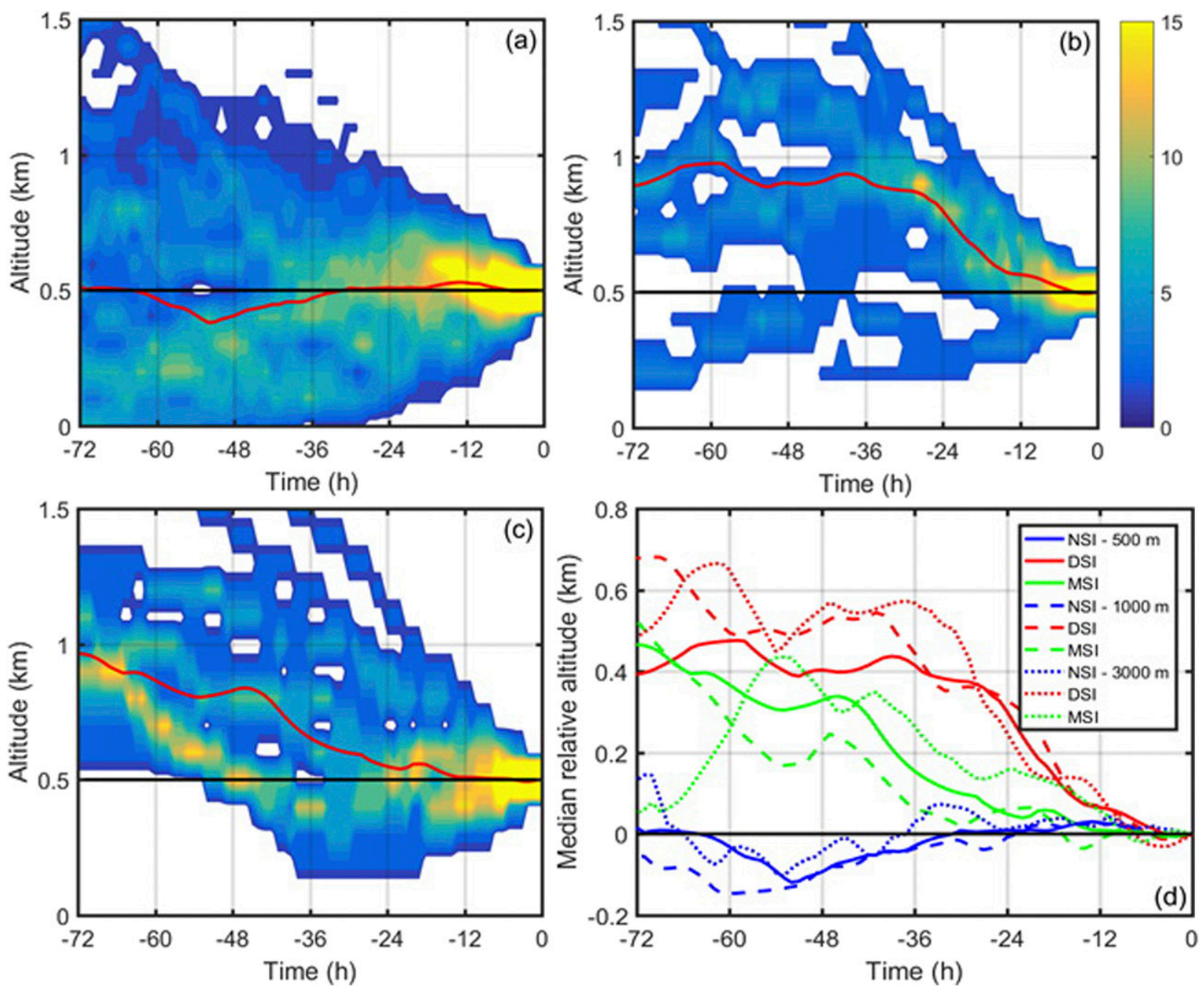

FIG. 10. As in Fig. 9, but for the vertical displacement of air reaching Oden at (a)-(c) $500 \mathrm{~m}$ above the surface for (a) NSI, (b) DSI, and (c) MSI. (d) The median relative displacement for the three different receptor heights is shown; see legend.

instrument is $50 \mathrm{~km}$; hence, all cases with higher visibility are excluded in the figure. The median visibility for NSIs is $\sim 11 \mathrm{~km}$, but the distribution has a broad minimum for this visibility and higher. For DSIs the median visibility increases to $\sim 38 \mathrm{~km}$. While DSIs also have a peak at visibilities associated with fog $(<1 \mathrm{~km})$, this occurs infrequently and there are more occasions with high visibility in DSIs than for the other categories. The probability for visibility below $1 \mathrm{~km}$ is highest for MSIs; a median visibility at $\sim 1 \mathrm{~km}$ indicates fog about half the time.

\section{c. Cloud fraction and cloud boundaries}

Figure 12a shows the distribution of the number of cloud layers from the cloud radar; the PDFs for all categories indicate that single-layer clouds were dominant. The PDFs qualitatively support the results from the LWP measurements; $\sim 37 \%$ of DSI radar profiles have zero layers. This is lower than the $50 \%$ suggested by the LWP, possibly reflecting a higher sensitivity of the cloud radar and/or the presence of ice clouds, seen by the radar but not the radiometer. NSIs are cloudiest, with clear skies $<10 \%$ of the time, followed by MSIs with $\sim 15 \%$ occurring during clear conditions; these numbers are also slightly different than those derived from the LWP. Figures 12b-d summarize statistics on cloud boundaries, using the ceilometer for cloud base and radar for cloud top. Note that these statistics can only be calculated when clouds are present, and hold no information on cloud fraction. To a first order, low cloud bases $(<100 \mathrm{~m})$ and low cloud tops $(<300 \mathrm{~m})$ and hence thin clouds $(<300 \mathrm{~m})$ dominate all classes. However, MSIs (DSIs) have a higher (lower), probability for the very lowest cloud bases and tops compared 

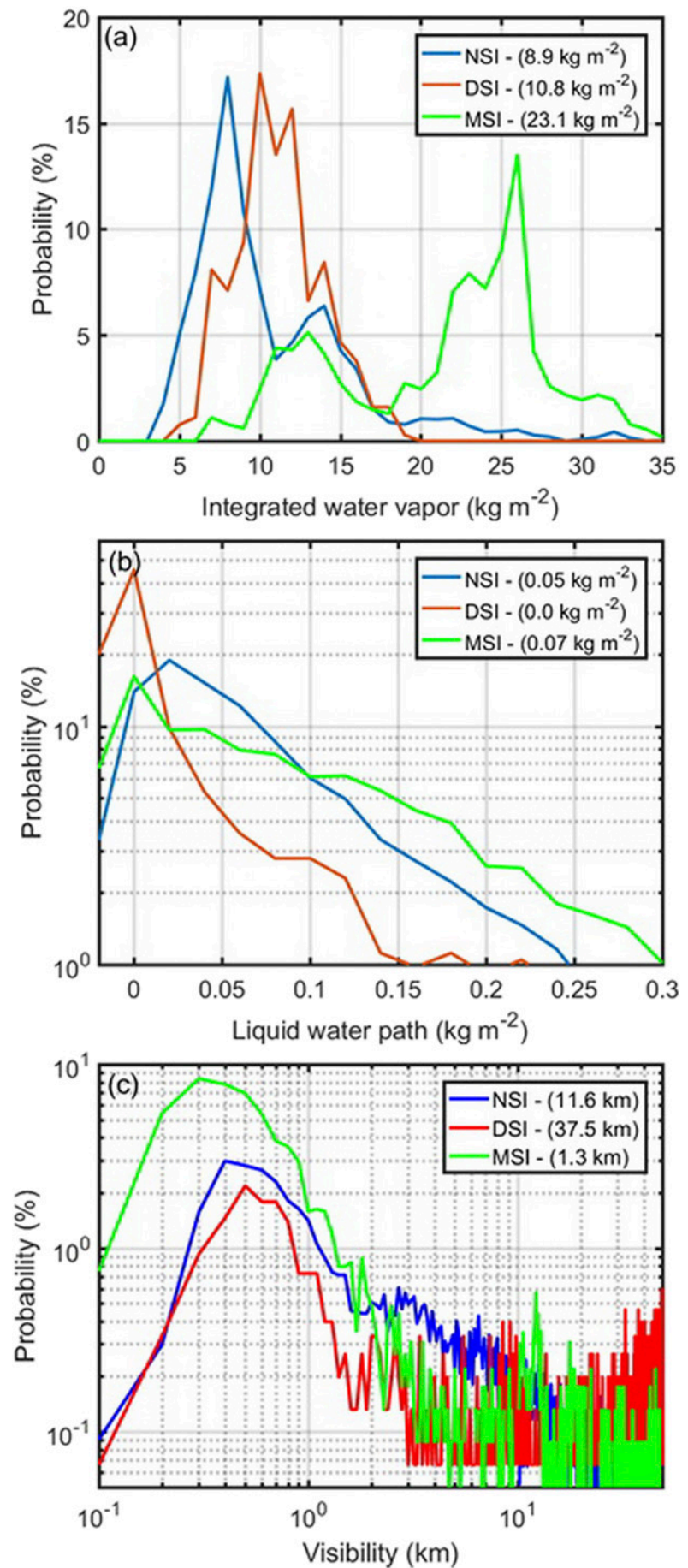

FIG. 11. Probability distributions of (a) IWV and (b) LWP (both in $\mathrm{kg} \mathrm{m}^{-2}$ ), and (c) visibility ( $\mathrm{km}$ ) for the three cases: NSI (blue), DSI (red), and MSI (green). The legends also give the median value for each distribution.

to NSIs. The thickness distributions (Fig. 12c) peak around $100 \mathrm{~m}$ for both DSIs and MSIs, in contrast to NSIs, which typically have thicker clouds, with peak values in the $100-300-m$ range. Figure 13 shows the probability of the cloud tops in relation to the depth of the surface inversion. The cloud or fog tops rarely extend to the top of the surface inversion, with peak probabilities at $\sim 0.4$ and $\sim 0.2 z z_{i}^{-1}$ for MSIs and DSIs, respectively.

Figure 14 shows the probability of radar reflectivity as a function of height. To the right of each panel is a vertical profile of cloud occurrence. The cloud fraction for NSIs is high (Fig. 14a), decreasing from $>90 \%$ below $200 \mathrm{~m}$ to less than $20 \%$ above $\sim 2 \mathrm{~km}$. The most frequently occurring reflectivity in the lowest few hundred meters is about $-25 \mathrm{dBZ}$, suggesting frequent nonprecipitating liquid-water clouds. Cloud fractions for MSIs (Fig. 14c) are slightly lower: $>60 \%$ below $100 \mathrm{~m}$, dropping to $<10 \%$ above $1 \mathrm{~km}$. These low values aloft are consistent with the finding that MSIs are associated with subsidence. The most frequently occurring reflectivity is also lower at $\sim-30 \mathrm{~dB} Z$. As expected, DSI mean cloud fractions are also substantially lower: $\leq 20 \%$ for all heights. Note that the $\sim 60 \%$ occurrence of zero cloud layers for DSIs in Fig. 12a, represents observations of the entire column. An interesting result in Fig. 14b is the high reflectivity values $(\sim 0 \mathrm{dBZ})$ for DSIs above $\sim 400 \mathrm{~m}$ coincident with a corresponding peak in Doppler fall velocities of $\sim 1 \mathrm{~m} \mathrm{~s}^{-1}$ (not shown). These values suggest precipitation-size particles, indicating that DSIs are sometimes found during transition periods, with deeper frontal clouds.

\section{d. Surface energy budget}

The characteristics analyzed above all ultimately have an effect on the surface energy budget. All components of the surface energy flux were either directly measured or estimated; here we define a positive flux as one adding energy to the surface and neglect subsurface fluxes.

Figure 15a shows the PDFs for surface net longwave radiation. For NSIs, the PDF has a single peak around $-10 \mathrm{~W} \mathrm{~m}^{-2}$, associated with cloudy conditions, with a tail down to $-60 \mathrm{~W} \mathrm{~m}^{-2}$, associated with cloudfree periods. The PDF for MSIs is similar, but shifted $\sim 15 \mathrm{~W} \mathrm{~m}^{-2}$ higher because the clouds are warmer than the surface as a result of the inversion. The difference in medians is $\sim 12 \mathrm{~W} \mathrm{~m}^{-2}$. Because of less cloud cover, the PDF for DSIs is bimodal, with well-separated peaks at -45 and $0 \mathrm{~W} \mathrm{~m}^{-2}$, corresponding to clear and cloudy conditions, respectively. The results for the turbulent (sensible plus latent) heat flux (Fig. 15b) are different. Here the PDFs for both DSIs and MSIs are similar, mostly positive with maxima between 0 and $20 \mathrm{~W} \mathrm{~m}^{-2}$, while for NSIs the PDF is broader and mostly negative, with a peak around -10 to $-15 \mathrm{~W} \mathrm{~m}^{-2}$. The difference between the MSI and NSI medians is much larger than for longwave radiation at $\sim 22 \mathrm{~W} \mathrm{~m}^{-2}$, indicating that 

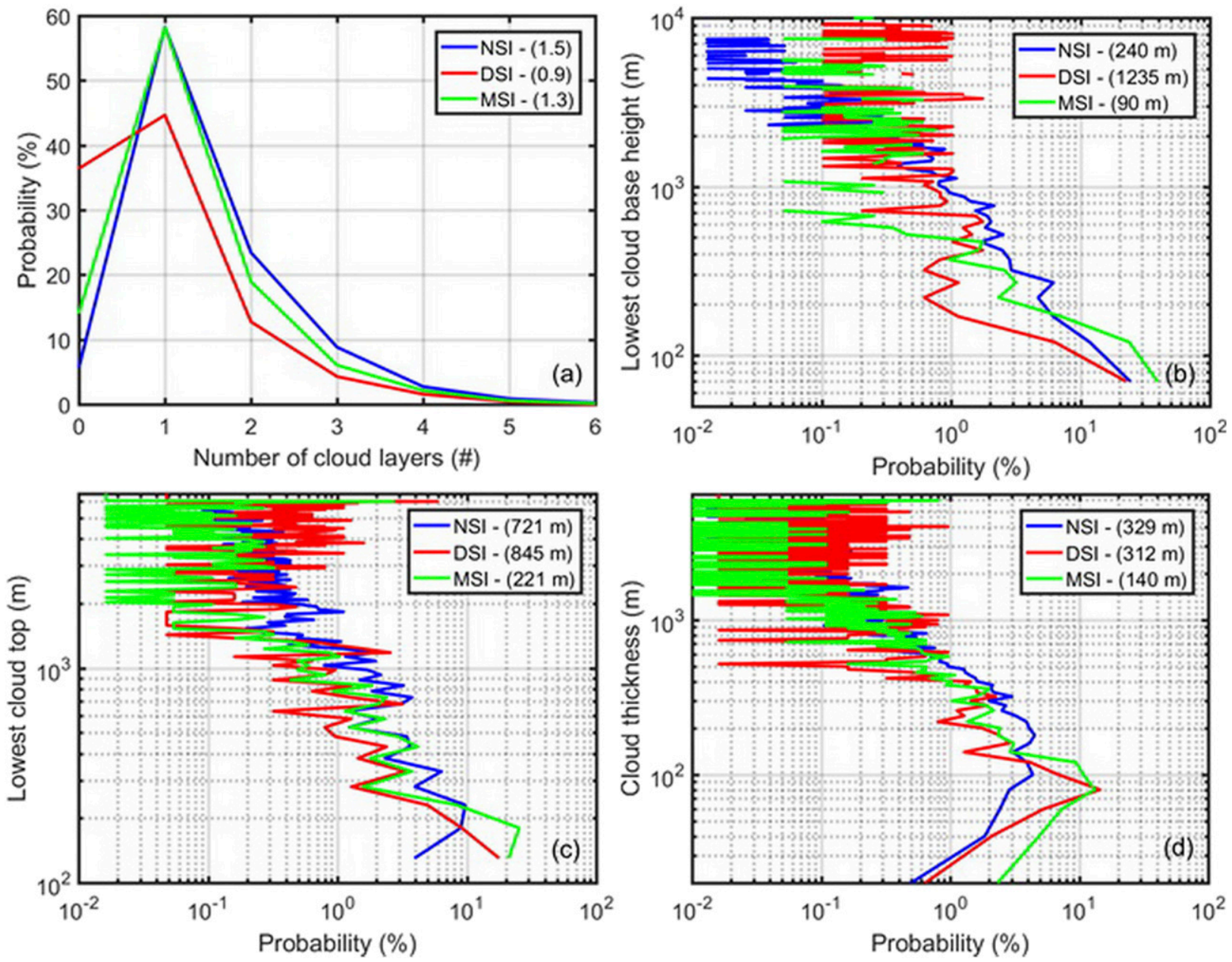

FIG. 12. As in Fig. 11, but for (a) the number of cloud layers from the cloud radar, (b) the lowest cloud-base height, (c) the lowest cloud-top height, and (d) the thickness of the lowest cloud layer. Units for (b)-(d) are meters; note their logarithmic scales.

the turbulent heat fluxes are more important than longwave radiation for the surface energy budget.

Figure $15 \mathrm{c}$ shows PDFs of the sum of the two terms. NSI and MSI PDFs are similar in shape, but the NSI PDF peaks at $\sim-20 \mathrm{~W} \mathrm{~m}^{-2}$, while the MSI PDF peaks at $+20 \mathrm{~W} \mathrm{~m}^{-2}$; the difference between medians is $\sim 36 \mathrm{~W} \mathrm{~m}^{-2}$. For the DSIs, there is less energy reaching the surface compared to NSIs by $\sim 10 \mathrm{~W} \mathrm{~m}^{-2}$. Hence, for MSIs both longwave radiation and turbulent fluxes contribute substantial additional energy to the surface compared to NSIs, in support of the hypothesis. For DSIs, turbulent fluxes also contribute extra energy; however, this is often outweighed by a loss of longwave radiation caused by frequent cloud-free conditions.

Figure 16a shows the estimated surface net solar radiation PDFs. The large median value for DSIs is due to relatively frequent occurrences in the $200-300 \mathrm{~W} \mathrm{~m}^{-2}$ range, caused by cloud-free conditions. When finally adding all the terms together for the full surface energy budget (Fig. 16b), MSIs have the highest median value $\left(\sim 62 \mathrm{~W} \mathrm{~m}^{-2}\right)$, followed by DSIs $\left(27 \mathrm{~W} \mathrm{~m}^{-2}\right)$, then NSIs $\left(8.4 \mathrm{~W} \mathrm{~m}^{-2}\right)$. The difference between MSI and NSI is over $50 \mathrm{~W} \mathrm{~m}^{-2}$, substantially larger than the values quoted in Tjernström et al. (2015), examining the strongest warm-air intrusion.

\section{Discussion}

While both turbulent fluxes and net longwave radiation are, to first order, dependent on the temperature differences between the surface and advected air (the surface inversion strength), the surface net solar radiation is partly external to the local system since it also depends on solar zenith angle, in addition to the local clouds and surface albedo. Therefore, the differences in net surface solar radiation among the three classes in Fig. 16a might be influenced by seasonal or spatial differences in occurrence of the three subsets of data. For 


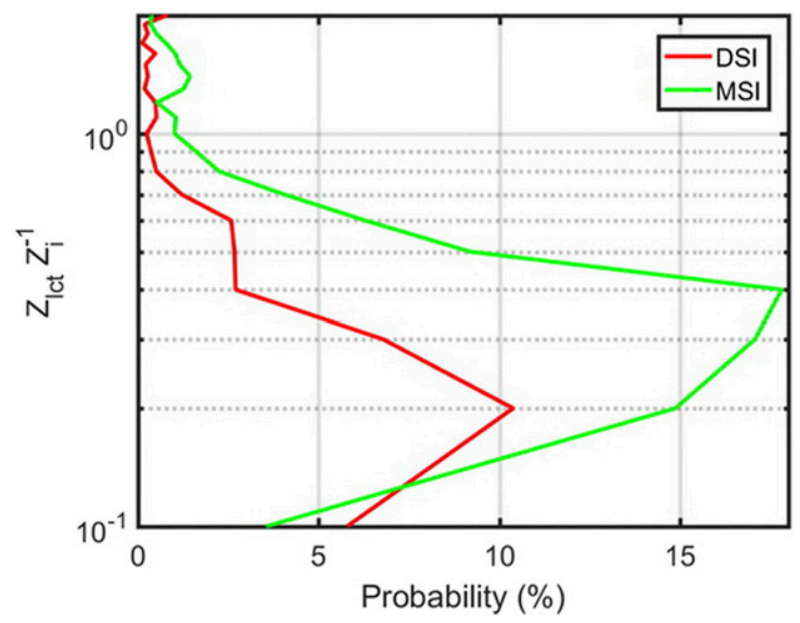

FIG. 13. As in Fig. 11, but for the normalized lowest cloud top $z_{\text {lct }}$, scaled with the depth of the surface inversion.

example, more downwelling solar radiation at TOA early in summer can potentially provide larger surface net flux even with attenuating clouds, compared to cloud-free conditions later in the year when downwelling solar radiation at TOA is lower. Hence, solar radiation presents a challenge for this analysis.

Figure 17a shows PDFs of calculated incoming shortwave radiation at the surface, assuming no clouds were present, from the Rapid Radiative Transfer Model (RRTM; Mlawer et al. 1997) using temperature and moisture profiles from radiosoundings. The different categories have distinct solar radiation distributions, with the largest clear-sky surface downwelling solar radiation coinciding with periods when surface inversions are present. It is therefore clear that there are differences in potential surface net solar radiation between these classes that are not due to the local conditions and therefore that, while Fig. 16b shows actual results from ACSE, these results cannot be used to directly test our hypothesis. The often-used cloud-radiative-effect concept also fails, since it also depends on the actual TOA solar radiation.

Figures $17 \mathrm{~b}$ and $17 \mathrm{c}$ shows a solar radiation neutral analysis of the effects of the clouds on surface solar radiation. Figure 17b shows the PDFs of the total transmissivity of the atmospheric column, dividing the observed incoming solar radiation by its theoretical TOA value, while Fig. 17c show the transmissivity of just the clouds, instead dividing it by the calculated clear-sky value. When calculating transmissivities, we ignored cases with very low incoming solar radiation (calculated clear-sky incoming shortwave $<5 \mathrm{~W} \mathrm{~m}^{-2}$ ). In both representations, the PDFs for NSIs and MSIs are strikingly similar while that for DSIs stand out by having a bimodal
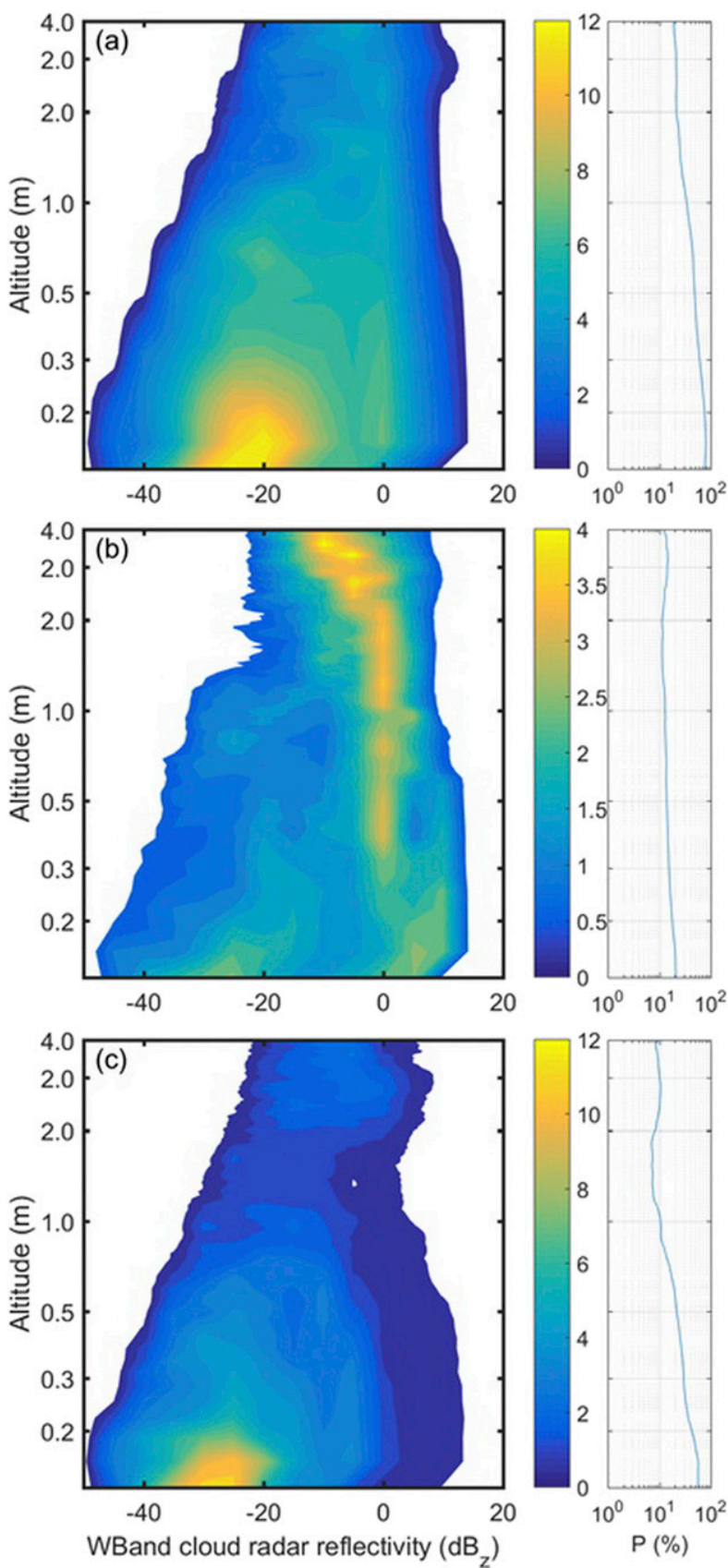

FIG. 14. (left) The probability of cloud radar reflectivity (dBZ) as a function of height for (a) NSIs, (b) DSIs, and (c) MSIs. (right) The mean cloud fraction $(\%)$ as a function of height for each category.

structure: one mode similar to NSIs and MSIs and one cloud-free mode. Hence, differences in cloud properties relevant for shortwave radiation are not responsible for the differences in surface net solar radiation. Therefore, it seems likely that the large differences in Fig. 16b are partly caused by differences in timing of the occurrence of the different classes. 

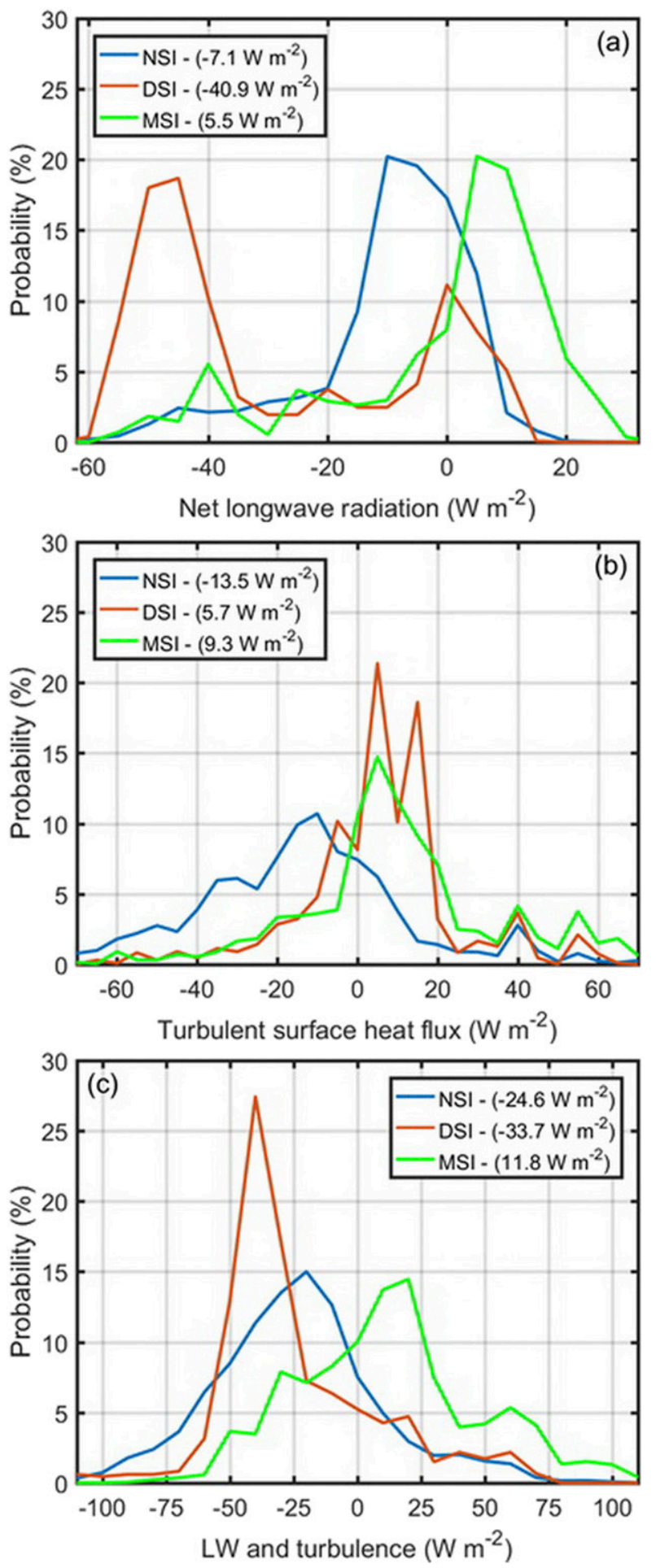

FIG. 15. As in Fig. 11, but for (a) surface net longwave radiation, (b) surface turbulent heat flux, and (c) the sum of the net longwave radiation and the turbulent heat flux at the surface $\left(\mathrm{W} \mathrm{m}^{-2}\right)$.
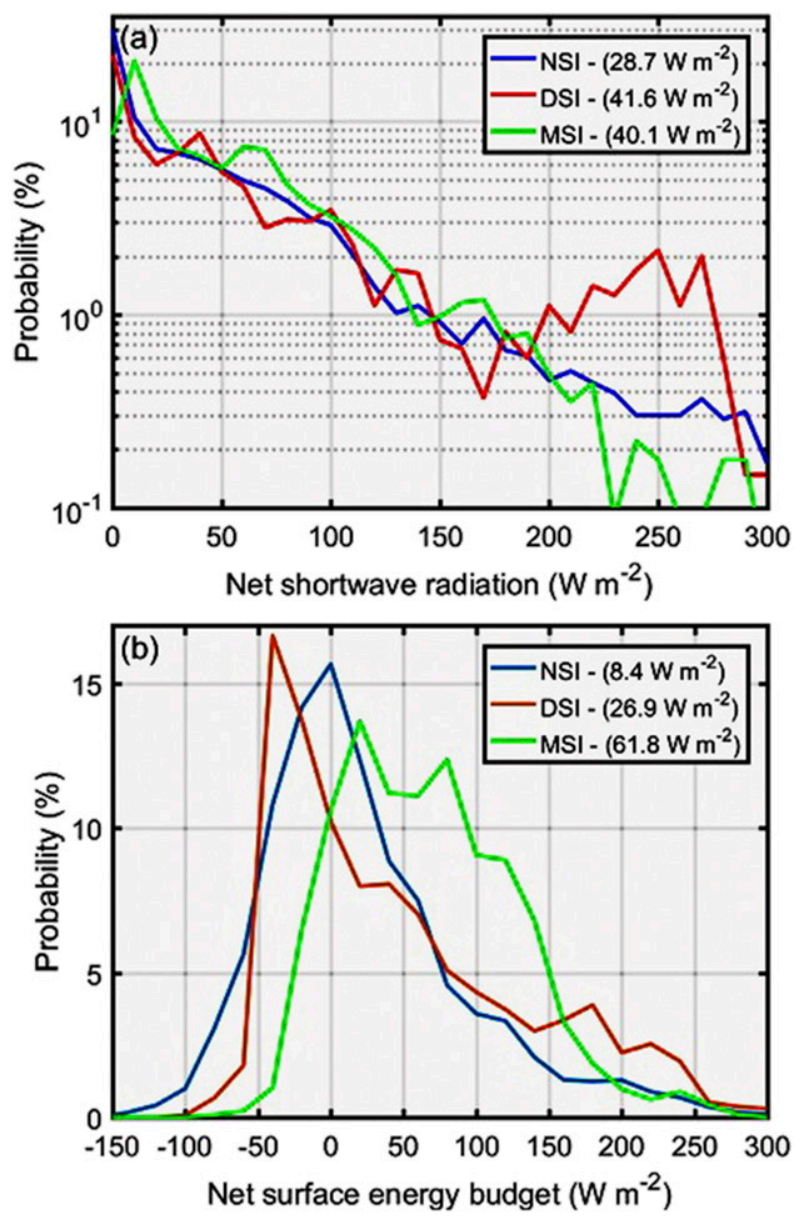

FIG. 16. As in Fig. 11, but for (a) surface net solar radiation and

(b) sum of all terms in the surface energy budget $\left(\mathrm{W} \mathrm{m}^{-2}\right)$.

To attempt to isolate the local atmospheric factors from the TOA solar radiation factors, we first calculate the time series of cloud transmissivity and surface albedo from the observations. We then select one particular day and calculate the net surface solar radiation for the whole time series, assuming all days have exactly the same TOA solar radiation as this day and using the albedo and transmissivity time series. Finally, we repeat this procedure using TOA solar radiation from different days from ACSE; for each time series of data we analyze the PDFs for both surface net solar radiation and total surface energy budget, assuming all conditions except solar radiation were as observed.

Examples from this analysis are shown in Fig. 18. If the TOA solar radiation were always as on DoY 200 (18 July; Fig. 18a), the sun is always above the horizon. The most common surface net solar radiation ranges from a few watts per square meter up to $100 \mathrm{~W} \mathrm{~m}^{-2}$; the median value is highest for DSIs, at $\sim 90 \mathrm{~W} \mathrm{~m}^{-2}$ because of the lower cloud cover, and lowest is for 

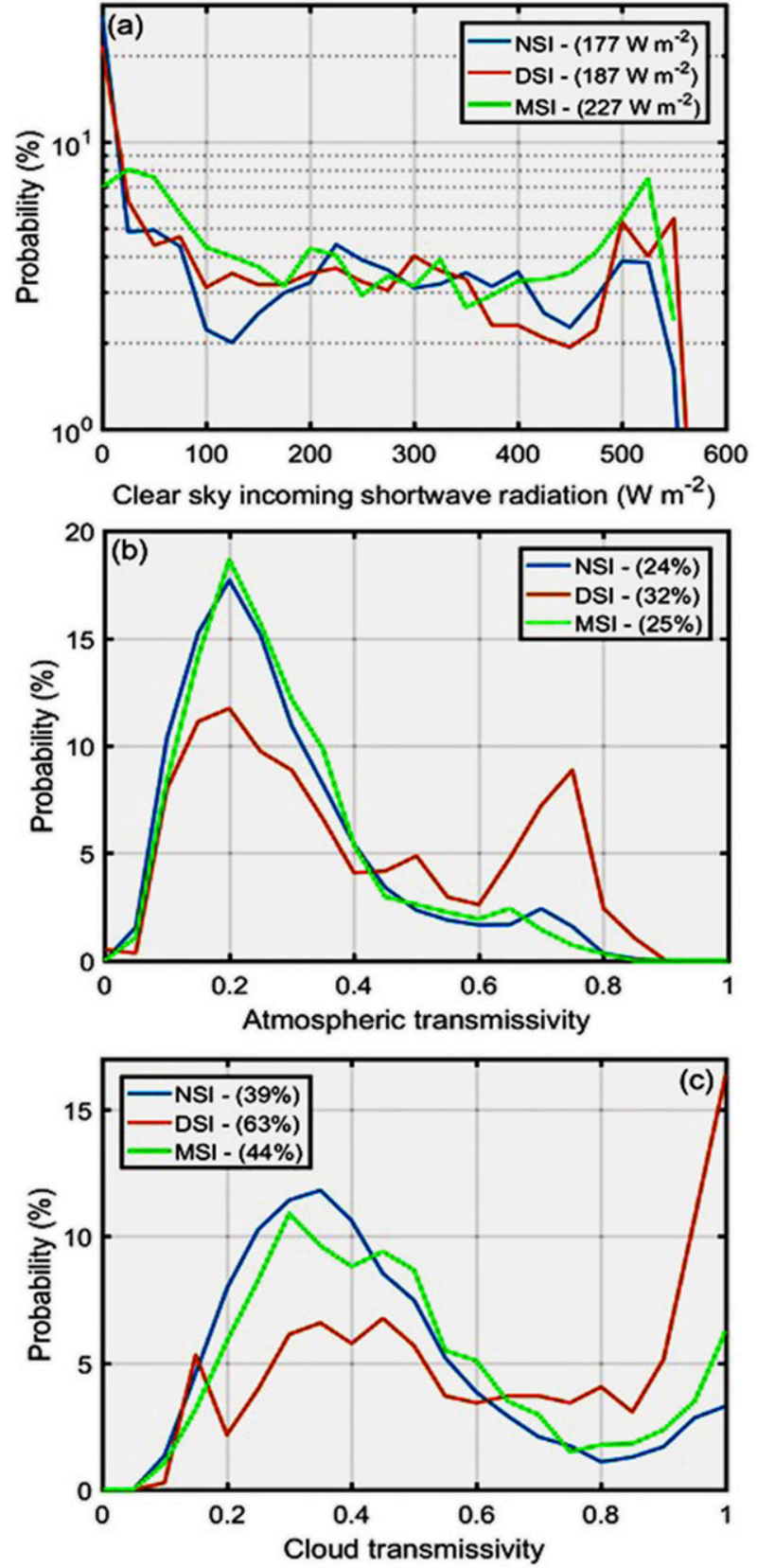

FIG. 17. As in Fig. 11, but for the (a) calculated incoming clearsky solar radiation at the surface $\left(\mathrm{W} \mathrm{m}^{-2}\right)$ and $(\mathrm{b})$ total atmospheric and (c) cloud transmissivities.

MSIs, $\sim 65 \mathrm{~W} \mathrm{~m}^{-2}$. However, adding all the terms in the surface energy budget (Fig. 18b) the net energy to the surface is still the highest for MSI: $13 \mathrm{~W} \mathrm{~m}^{-2}$ higher than for NSI, also higher than DSI. Hence, comparing MSI and NSI, for this day the increase in surface net longwave radiation is partly cancelled by the reduction in the surface net solar radiation. Using solar radiation from 60 days later, DoY 260 (16 September; Fig. 18c), the sun was below the horizon for part of the diurnal cycle and hence the most common occurrence is at zero with most positive occurrences $<25 \mathrm{~W} \mathrm{~m}^{-2}$. Median net solar radiation values span $1-13 \mathrm{~W} \mathrm{~m}^{-2}$, highest for NSIs and lowest for MSIs. However, when considering all terms in the surface energy budget (Fig. 18d), MSIs again exhibit the largest energy flux to the surface.

Of course, even later, when solar radiation stops playing a role altogether, the effects of the diabatically fixed surface temperature will disappear as the surface starts to freeze and the temperature is able to respond to changes in the surface energy budget, dropping below freezing. Advection of warm and moist air will still be important, but acting to modulate ice growth (e.g., Persson et al. 2017). Other factors might also contribute and clearly data from one expedition during a specific year is insufficient to determine if the conditions observed here are more common during certain parts of the summer or not.

Summarizing, during the melt season MSIs have a larger downward flux of energy to the surface than NSIs, ranging from a surplus of $\sim 10 \mathrm{~W} \mathrm{~m}^{-2}$ in summer, when solar radiation is relatively strong, to $\sim 25 \mathrm{~W} \mathrm{~m}^{-2}$ in autumn, when the sun is beginning to settle below the horizon during local night and the zenith angle is larger. These numbers are comparable to those quoted in Tjernström et al. (2015).

\section{Conclusions}

Inspired by the characteristics of an extreme warmair-advection episode in August 2014, during the Arctic Clouds in Summer Experiment (Tjernström et al. 2015), we analyze all surface-temperature inversions during the entire expedition, from early July to early October, to explore a hypothesis related to airmass transformation near the sea ice edge. The hypothesis states that advection of warm air over melting sea ice leads to formation of a surface inversion, often with embedded fog. This increases the net surface longwave radiation and downward turbulent heat flux in a zone downwind from the ice edge sufficiently that any reduction of surface net shortwave radiation by the clouds is overcome and the net heat flux to the surface is enhanced beyond the well-established surface-warming effects of clouds in the Arctic. Exploring only cases where sea ice concentration was $>15 \%$, our main conclusions are as follows:

- Surface temperature inversions over sea ice during ACSE occurred $33 \%$ of the time and occurred in two categories, moist and dry, here defined as when moisture changed by more or less than $1 \mathrm{~g} \mathrm{~kg}^{-1}$ across the inversion, respectively. Inversion strength $\Delta T$ was 

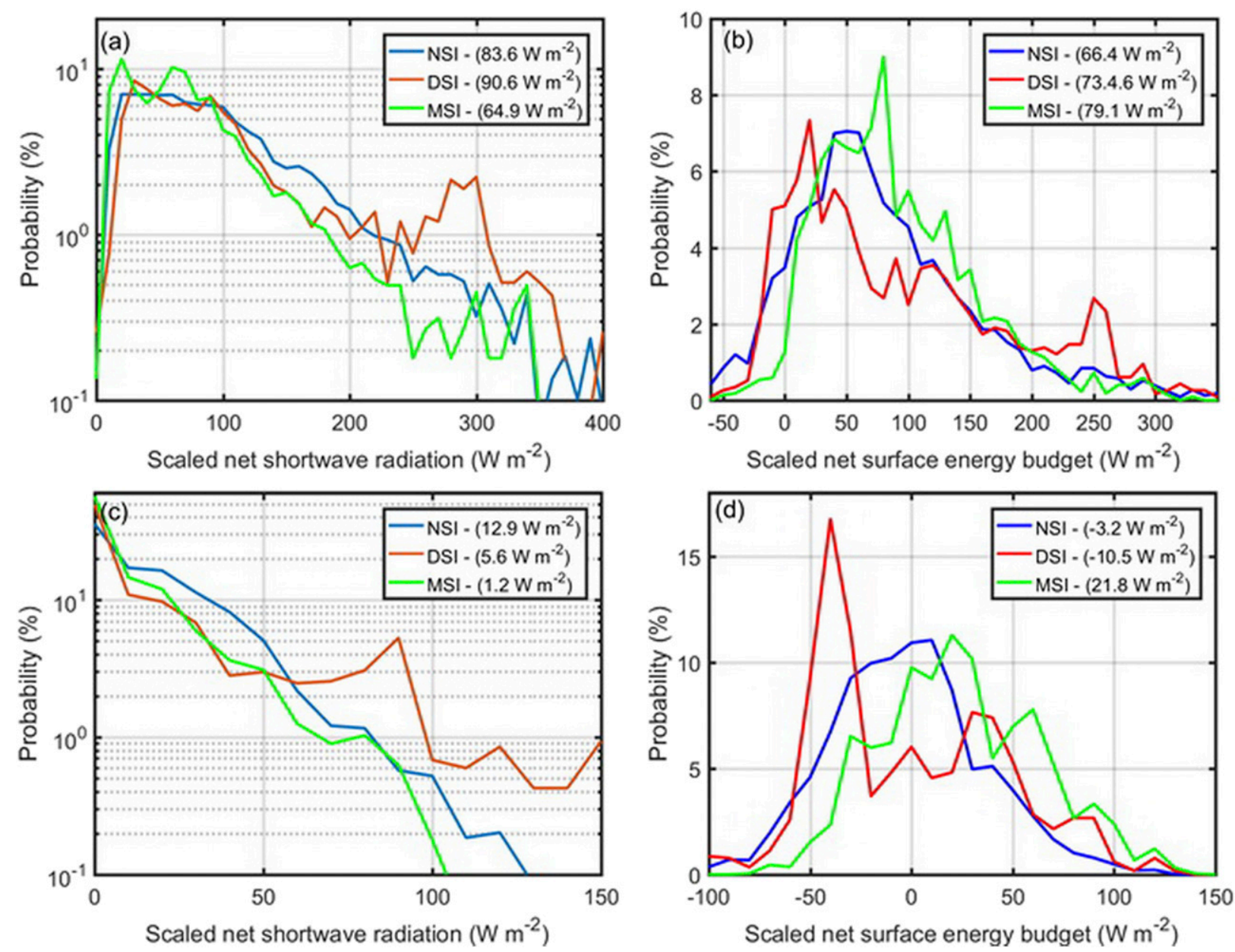

FIG. 18. As in Fig. 11, but for the calculated surface (a),(c) net solar radiation and (b),(d) total net surface energy budget (W $\mathrm{m}^{-2}$ ) assuming all days were like (a),(b) DoY 200 and (c),(d) DoY 260.

largest when moisture increase $\Delta Q$ was also large and moist inversions were typically deeper and stronger $\left(\Delta T \sim 4^{\circ}-15^{\circ} \mathrm{C}\right.$ and $\left.\Delta z \sim 300-800 \mathrm{~m}\right)$ than dry inversions $\left(\Delta T \sim 2^{\circ}-6^{\circ} \mathrm{C}\right.$ and $\left.\Delta z \sim 100-300 \mathrm{~m}\right)$.

- In moist inversions, consistent presence of optically thick warm fog or low clouds combined with stable stratification led to consistently larger net downward heat flux to the surface by $10-25 \mathrm{~W} \mathrm{~m}^{-2}$, compared to cases without a surface inversion. Moist inversions had significantly larger IWV and LWP than cases without surface inversions. Similar to cases without surface inversion, they had $80 \%-95 \%$ cloud cover on average but low visibility $(<1 \mathrm{~km})$ appeared more frequently.

- Although dry inversions also featured high relative humidity, cloud-free conditions were found in this category more often than in any other. Dry surface inversions had slightly higher IWV but significantly lower LWP, with indications of frequent cloud-free periods; on average $50 \%-80 \%$ cloud cover, depending on what instrument is interrogated.

- Since optically thick clouds have opposing effects on the net surface longwave and shortwave radiation, the largest increase in downward surface energy flux for moist inversions came from the turbulent heat flux; about twice that for the surface net longwave radiation. Dry inversions exhibited a similar increase in surface turbulent heat flux but here the radiation terms dominated.

- Surface inversions were predominantly found with air coming from the south, covering $\sim 400 \mathrm{~km}$ of distance under a subsidence of $0.2-0.4 \mathrm{~cm} \mathrm{~s}^{-1}$ over the $24-36 \mathrm{~h}$ preceding arrival at $O d e n$.

Based on these results, parts of our hypothesis is confirmed. Surface inversions over melting sea ice occur with advection of warm air from the south. Additionally, as indicated by the apparent subsidence, this seems 
to occur in high pressure situations; this also reinforces the static stability. It is also confirmed that most often moisture increases substantially with height and that fog is common, leading to the hypothesized additional surface heating. However, unexpectedly, for inversion cases where moisture was constant or decreased with height, the amount of low clouds or fog was substantially lower than for any other set of conditions, causing a large reduction in surface net longwave radiation and a somewhat compensating increase in surface net shortwave radiation.

Moreover, the parts of our hypothesis regarding the downwind transformation to a near-adiabatic cloudcapped boundary layer could not be considered here, with data limited to locations near the ice edge. However, it should be noted that almost all central Arctic summer observations consistently reveal this structure [see Tjernström et al. (2012) for a summary].

Thus, while answering some questions, this study raises others. A main question relates to the atmospheric dynamics responsible for the different states discussed in this paper. For example, while we found surface inversions when the flow was from the south and associated with descending trajectories, it would be interesting to better characterize the details of the synoptic-scale weather systems that force moist versus dry surface inversions. Also, these results indicate that turbulent heat flux was more important than the changes in radiation caused by clouds, and stably stratified turbulence remains a poorly understood area of ABL flows (Holtslag et al. 2013). Often, as the static stability increases the momentum flux is reduced and hence the near-surface wind speed is also reduced. Here that is not the case, which is interesting in itself; possibly this constitutes another linkage between the larger-scale flow and small-scale processes.

While these aspects are beyond the scope of this paper, constructive avenues to continue this line of inquiry should be explored. The further downstream development of air masses must be addressed in a Lagrangian framework, and hence should be explored with new ideas on how to analyze and perform observations and design modeling experiments (cf. e.g., Pithan et al. 2018). Numerical modeling on different scales constitute one way forward, for example single-column or largeeddy modeling at different locations using advection tendencies from reanalysis (e.g., Sotiropoulou et al. 2018; Hartung et al. 2018), or Lagrangian modeling where a hypothetical atmospheric column is advected along a trajectory over the observed surface conditions (Sotiropoulou 2016; Pithan et al. 2014). Modeling needs to be informed by observations, and observation design may also need to consider a Lagrangian framework, as was pioneered in ASTEX (Albrecht et al. 1995) but rarely repeated. Other observational avenues to explore include analysis of satellite data along trajectories calculated from reanalysis.

Acknowledgments. The authors are grateful to Ola Persson, Georgia Sotiropoulou, Barbara Brooks, Dominic Salisbury, Dan Wolfe, and Paul Johnston for their participation during the ACSE field campaign. We are also grateful to the two captains and crews of Oden for practical help and to the Swedish Polar Research Secretariat for arranging the expedition. MT acknowledges funding from the Knut and Alice Wallenberg Foundation (KAW 2011.2007), the Office of Naval Research (N000141210235), the Swedish Research Council (2013-5334 and 2012-5098), and Stockholm University, Faculty of Science (SU FV-5.1.2-2419-13). MS was supported by the U.S. Department of Energy Atmospheric System Research Program (DE-SC0011918). IB, PA, and JP were funded by U.K. Natural Environment Research Council (Grant NE/K011820/1). The lidar, HATPRO radiometer, and the radiosounding system were provided by the Atmospheric Measurement Facility of the U.K. National Centre for Atmospheric Science, while the cloud radar and radiometrics microwave radiometer were provided by the NOAA/Earth System Research Laboratory. The present work was done while MT was on a sabbatical at the National Center for Atmospheric Research (NCAR) in Boulder, Colorado, and MT is grateful for discussions with and support from colleagues at NCAR. The data are available at the Bolin Center (www.bolin.su.se/data).

\section{REFERENCES}

Achtert, P., I. M. Brooks, B. J. Brooks, B. I. Moat, J. Prytherch, P. O. G. Persson, and M. Tjernström, 2015: Measurement of wind profiles over the Arctic Ocean from ship-borne Doppler lidar. Atmos. Meas. Tech., 8, 4993-5007, https://doi.org/10.5194/ amt-8-4993-2015.

Albrecht, B. A., C. S. Bretherton, D. Johnson, W. H. Schubert, and A. S. Frish, 1995: The Atlantic Stratocumulus Transition Experiment-ASTEX. Bull. Amer. Meteor. Soc., 76, 889-904, https://doi.org/10.1175/1520-0477(1995)076<0889: TASTE $>2.0 . \mathrm{CO} ; 2$.

Bintanja, R., E. C. van der Linden, and W. Hazeleger, 2012: Boundary layer stability and Arctic climate change: A feedback study using EC-Earth. Climate Dyn., 39, 2659-2673, https://doi.org/10.1007/s00382-011-1272-1.

Blunden, J., and D. S. Arndt, 2017: The Arctic [in "State of the Climate in 2016"]. Bull. Amer. Meteor. Soc., 98 (8), S93-S128.

Brooks, I. M., and Coauthors, 2017: The turbulent structure of the Arctic summer boundary layer during the Arctic Summer Cloud-Ocean Study. J. Geophys. Res. Atmos., 122, 9685-9704, https://doi.org/10.1002/2017JD027234. 
Cai, M., and K.-K. Tung, 2012: Robustness of dynamical feedbacks from radiative forcing: $2 \%$ solar versus $2 \times 3 \mathrm{CO}_{2}$ experiments in an idealized GCM. J. Atmos. Sci., 69, 2256-2271, https:// doi.org/10.1175/JAS-D-11-0117.1.

Cao, Y., S. Liang, X. Chen, T. He, D. Wang, and X. Cheng, 2017: Enhanced wintertime greenhouse effect reinforcing Arctic amplification and initial sea-ice melting. Sci. Rep., 7, 8462, https://doi.org/10.1038/s41598-017-08545-2.

Cox, C. J., T. Uttal, C. Long, M. D. Shupe, R. S. Stone, and S. Starkweather, 2016: The role of springtime, Arctic clouds in determining autumn sea ice extent. J. Climate, 29, 6581-6596, https://doi.org/10.1175/JCLI-D-16-0136.1.

Dee, D. P., and Coauthors, 2011: The ERA-Interim reanalysis: Configuration and performance of the data assimilation system. Quart. J. Roy. Meteor. Soc., 137, 553-597, https://doi.org/ 10.1002/qj.828.

Edson, J. B., A. A. Hinton, K. E. Prada, J. E. Hare, and C. W. Fairall, 1998: Direct covariance flux estimates from mobile platforms at sea. J. Atmos. Oceanic Technol., 15, 547-562, https:// doi.org/10.1175/1520-0426(1998)015<0547:DCFEFM>2.0.CO;2.

Fletcher, C. G., S. C. Hardiman, P. J. Kushner, and J. Cohen, 2009: The dynamical response to snow cover perturbations in a large ensemble of atmospheric GCM integrations. J. Climate, 22, 1208-1222, https://doi.org/10.1175/2008JCLI2505.1.

Gillett, N. P., D. A. Stone, P. A. Stott, T. Nozawa, A. Yu. Karpechko, G. C. Hegerl, M. F. Wehner, and P. D. Jones, 2008: Attribution of polar warming to human influence. Nat. Geosci., 1, 750-754, https://doi.org/10.1038/ngeo338.

Graham, R. M., and Coauthors, 2017: A comparison of the two arctic atmospheric winter states observed during N-ICE2015 and SHEBA. J. Geophys. Res. Atmos., 122, 5716-5737, https:// doi.org/10.1002/2016JD025475.

Graversen, R. G., T. Mauritsen, M. Tjernström, E. Källén and G. Svensson, 2008: Vertical structure of recent Arctic warming. Nature, 541, 53-56, https://doi.org/10.1038/nature06502.

— — — - S. Drijfhout, M. Tjernström, and S. Mårtensson, 2011: Warm winds from the Pacific caused extensive Arctic sea-ice melt in summer 2007. Climate Dyn., 36, 2103-2112, https://doi. org/10.1007/s00382-010-0809-z.

Hartung, K., G. Svensson, H. Struthers, A.-L. Deppenmeier, and W. Hazeleger, 2018: An EC-Earth coupled atmosphere-ocean single-column model (AOSCM.v1_EC-Earth3) for studying coupled marine and polar processes. Geosci. Model Dev., 11, 4117-4137, https://doi.org/10.5194/gmd-11-4117-2018.

Holtslag, B., and Coauthors, 2013: Stable atmospheric boundary layers and diurnal cycles-Challenges for weather and climate models. Bull. Amer. Meteor. Soc., 94, 1691-1706, https:// doi.org/10.1175/BAMS-D-11-00187.1.

Intrieri, J. M., C. W. Fairall, M. D. Shupe, P. O. G. Persson, E. L. Andreas, P. Guest, and R. M. Moritz, 2002: An annual cycle of Arctic surface cloud forcing at SHEBA. J. Geophys. Res., 107, 8039, https://doi.org/10.1029/2000JC000439.

IPCC, 2013: Summary for policymakers. Climate Change 2013: The Physical Science Basis, T. F. Stocker et al., Eds., Cambridge University Press, 1-29.

Kapsch, M.-L., R. G. Graversen, and M. Tjernström, 2013: Springtime atmospheric transport controls Arctic summer sea ice. Nat. Climate Change, 3, 744-748, https://doi.org/10.1038/ nclimate1884.

- — - T. Economou, and M. Tjernström, 2014: The importance of spring atmospheric conditions for the prediction of Arctic summer sea-ice extent. Geophys. Res. Lett., 41, 52885296, https://doi.org/10.1002/2014GL060826.
,-- M. Tjernström, and R. Bintanja, 2016: The effect of downwelling longwave radiation on Arctic summer sea ice. J. Climate, 29, 1143-1159, https://doi.org/10.1175/JCLI-D-150238.1.

Kay, J. E., and A. Gettelman, 2009: Cloud influence on and response to seasonal Arctic sea ice loss. J. Geophys. Res., 114, D18204, https://doi.org/10.1029/2009JD011773.

Koenigk, T., and Coauthors, 2013: Arctic climate change in the 21st century in an ensemble of AR5 scenario projections with ECEarth. Climate Dyn., 40, 2719-2743, https://doi.org/10.1007/ s00382-012-1505-y.

Leck, C., E. D. Nilsson, E. K. Bigg, and L. Bäcklin, 2001: Atmospheric program on the Arctic Ocean Expedition 1996 (AOE1996): An overview of scientific goals, experimental approach, and instruments. J. Geophys. Res., 106, 32 051-32 067, https:// doi.org/10.1029/2000JD900461.

Liu, Y., and J. R. Key, 2014: Less winter cloud aids summer 2013 Arctic sea ice return from 2012 minimum. Environ. Res. Lett., 9, https://doi.org/10.1088/1748-9326/9/4/044002.

Mauritsen, T., and Coauthors, 2011: An Arctic CCN-limited cloudaerosol regime. Atmos. Chem. Phys., 11, 165-173, https://doi.org/ 10.5194/acp-11-165-2011.

Min, S.-K., X. Zhang, F. W. Zwiers, and T. Agnew, 2008: Human influence on Arctic sea ice detectable from early 1990s onwards. Geophys. Res. Lett., 35, L21701, https://doi.org/10.1029/ 2008 GL035725.

Mlawer, E. J., S. J. Taubman, P. D. Brown, M. J. Iacono, and S. A. Clough, 1997: Radiative transfer for inhomogeneous atmospheres: RRTM, a validated correlated-k model for the longwave.J. Geophys. Res., 102, 16663-16 682, https://doi.org/ 10.1029/97JD00237.

Moat, B. I., M. J. Yelland, and I. M. Brooks, 2015: Airflow distortion at instrument sites on the ODEN during the ACSE project. National Oceanography Centre, Southampton, United Kingdom, Internal Document 17, https:// eprints.soton.ac.uk/385311/.

Moran, K. P., S. Pezoa, C. W. Fairall, C. R. Williams, T. E. Ayers, A. Brewer, S. P. de Szoeke, and V. Ghate, 2012: A motionstabilized W-band radar for shipboard observations of marine boundary-layer clouds. Bound.-Layer Meteor., 143, 3-24, https://doi.org/10.1007/s10546-011-9674-5.

Morrison, H., G. de Boer, G. Feingold, J. Harrington, M. D. Shupe, and K. Sulia, 2012: Resilience of persistent Arctic mixed-phase clouds. Nat. Geosci., 5, 11-17, https://doi.org/10.1038/ngeo1332.

Mortin, J., G. Svensson, R.-G. Graversen, M.-L. Kapsch, J. C. Stroeve, and L. N. Boisvert, 2016: Melt onset over Arctic sea ice controlled by atmospheric moisture transport. Geophys. Res. Lett., 43, 6636-6642, https://doi.org/10.1002/2016GL069330.

Naakka, T., T. Nygård, T. Vihma, J. Sedlar, and R. Graversen, 2018: Atmospheric moisture transport between mid-latitudes and the Arctic: Regional, seasonal and vertical distributions. Int. J. Climatol., in press.

Perovich, D. K., T. C. Grenfell, B. Light, and P. V. Hobbs, 2002: Seasonal evolution of the albedo of multiyear Actic sea ice. J. Geophys. Res., 107, 8044, https://doi.org/10.1029/ $2000 \mathrm{JC} 000438$.

, B. Light, H. Eicken, K.-F. Jones, K. Runciman, and S. V. Nghiem, 2007: Increasing solar heating of the Arctic Ocean and adjacent seas, 1979-2005: Attribution and role in the ice-albedo feedback. Geophys. Res. Lett., 34, L19505, https:// doi.org/10.1029/2007GL031480.

Persson, P. O. G., 2012: Onset and end of the summer melt season over sea ice: Thermal structure and surface energy perspective 
from SHEBA. Climate Dyn., 39, 1349-1371, https://doi.org/ 10.1007/s00382-011-1196-9.

— M. D. Shupe, D. Perovich, and A. Solomon, 2017: Linking atmospheric synoptic transport, cloud phase, surface energy fluxes, and sea-ice growth: Observations of midwinter SHEBA conditions. Climate Dyn., 49, 1341-1364, https://doi.org/10.1007/ s00382-016-3383-1.

Pithan, F., and T. Mauritsen, 2014: Arctic amplification dominated by temperature feedbacks in contemporary climate models. Nat. Geosci., 7, 181-184, https://doi.org/10.1038/ ngeo2071.

— B. Medeiros, and T. Mauritsen, 2014: Mixed-phase clouds cause climate model biases in Arctic wintertime temperature inversions. Climate Dyn., 43, 289-303, https://doi.org/10.1007/ s00382-013-1964-9.

- , and Coauthors, 2018: Role of air-mass transformations in exchange between the Arctic and mid-latitudes. Nat. Geosci., 11, 805-812, https://doi.org/10.1038/s41561-018-0234-1.

Polyakov, I. V., and Coauthors, 2010: Arctic ocean warming contributes to reduced polar ice cap. J. Phys. Oceanogr., 40, $2743-$ 2756, https://doi.org/10.1175/2010JPO4339.1.

Prytherch, J., M. J. Yelland, I. M. Brooks, D. J. Tupman, R. W. Pascal, B. I. Moat, and S. J. Norris, 2015: Motion-correlated flow distortion and wave-induced biases in air-sea flux measurements from ships. Atmos. Chem. Phys., 15, 10 619-10 629, https://doi.org/10.5194/acp-15-10619-2015.

Schröder, D., D. L. Feltham, D. Flocco, and M. Tsamados, 2014: September Arctic sea-ice minimum predicted by spring melt-pond fraction. Nat. Climate Change, 4, 353-357, https:// doi.org/10.1038/nclimate2203.

Sedlar, J., 2014: Implications of limited liquid water path on static mixing within Arctic low-level clouds. J. Appl. Meteor. Climatol., 53, 2775-2789, https://doi.org/10.1175/JAMC-D-140065.1.

__ , and A. Devasthale, 2012: Clear-sky thermodynamic and radiative anomalies over a sea ice sensitive region of the Arctic. J. Geophys. Res., 117, D19111, https://doi.org/10.1029/ 2012JD017754.

—_, and M. Tjernström, 2017: Clouds, warm air and a climate cooling signal over the summer Arctic. Geophys. Res. Lett., 44, 1095-1103, https://doi.org/10.1002/2016GL071959.

_- and Coauthors, 2011: A transitioning Arctic surface energy budget: The impacts of solar zenith angle, surface albedo and cloud radiative forcing. Climate Dyn., 37, 1643-1660, https:// doi.org/10.1007/s00382-010-0937-5.

— M. D. Shupe, and M. Tjernström, 2012: On the relationship between thermodynamic structure and cloud top, and its climate significance in the Arctic. J. Climate, 25, 2374-2393, https://doi.org/10.1175/JCLI-D-11-00186.1.

Serreze, M. C., and J. A. Francis, 2006: The Arctic amplification debate. Climatic Change, 76, 241-264, https://doi.org/10.1007/ s10584-005-9017-y

— plification: A research synthesis. Global Planet. Change, 77, 85-96, https://doi.org/10.1016/j.gloplacha.2011.03.004.

Shimada, K., T. Kamoshida, M. Itoh, S. Nishino, E. Carmack, F. McLaughlin, S. Zimmermann, and A. Proshutinsky, 2006: Pacific Ocean inflow: Influence on catastrophic reduction of sea ice cover in the Arctic Ocean. Geophys. Res. Lett., 33, L08605, https://doi.org/10.1029/2005GL025624.

Shupe, M. D., and J. M. Intrieri, 2004: Cloud radiative forcing of the Arctic surface: The influence of cloud properties, surface albedo, and solar zenith angle. J. Climate, 17, 616-628,
https://doi.org/10.1175/1520-0442(2004)017<0616:CRFOTA $>$ 2.0.CO;2.

_ S. Y. Matrosov, and T. Uttal, 2006: Arctic mixed-phase cloud properties derived from surface-based sensors at SHEBA. J. Atmos. Sci., 63, 697-711, https://doi.org/10.1175/JAS3659.1.

—, V. P. Walden, E. Eloranta, T. Uttal, J. R. Campbell, S. M. Starkweather, and M. Shiobara, 2011: Clouds at Arctic atmospheric observatories. Part I: Occurrence and macrophysical properties. J. Appl. Meteor. Climatol., 50, 626-644, https://doi.org/10.1175/2010JAMC2467.1.

_ , P. O. G. Persson, I. M. Brooks, M. Tjernstrom, J. Sedlar, T. Mauritsen, S. Sjogren, and C. Leck, 2013: Cloud and boundary layer interactions over the Arctic sea ice in late summer. Atmos. Chem. Phys., 13, 9379-9400, https://doi.org/ 10.5194/acp-13-9379-2013.

Sotiropoulou, G., 2016: The Arctic atmosphere: Interactions between clouds, boundary-layer turbulence and large-scale circulation. Ph.D. dissertation, Department of Meteorology, Stockholm University, 49 pp., https://www.diva-portal.org/ smash/get/diva2:1033927/FULLTEXT02.pdf.

—, J. Sedlar, M. Tjernström, M. D. Shupe, I. M. Brooks, and P. O. G. Persson, 2014: The thermodynamic structure of summer Arctic stratocumulus and the dynamic coupling to the surface. Atmos. Chem. Phys., 14, 12 573-12 592, https:// doi.org/10.5194/acp-14-12573-2014.

— , and Coauthors, 2016: Atmospheric conditions during the Arctic Clouds in Summer Experiment (ACSE): Contrasting open-water and sea-ice surfaces during melt and freeze-up seasons. J. Climate, 29, 8721-8744, https://doi.org/10.1175/ JCLI-D-16-0211.1.

— M. Tjernström, J. Savre, A. M. L. Ekman, K. Hartung, and J. Sedlar, 2018: Large-eddy simulation of a warm-air advection episode in the summer Arctic. Quart. J. Roy. Meteor. Soc., 144, 2449-2462, https://doi.org/10.1002/qj.3316.

Spreen, G., L. Kaleschke, and G. Heygster, 2008: Sea ice remote sensing using AMSR-E $89 \mathrm{GHz}$ channels. J. Geophys. Res., 113, C02S03, https://doi.org/10.1029/2005JC003384.

Stein, A. F., R. R. Draxler, G. D. Rolph, B. J. B. Stunder, M. D. Cohen, and F. Ngan, 2015: NOAA's HYSPLIT atmospheric transport and dispersion modeling system. Bull. Amer. Meteor. Soc., 96, 2059-2077, https://doi.org/10.1175/BAMS-D-14-00110.1.

Tjernström, M., 2005: The summer Arctic boundary layer during the Arctic Ocean Experiment 2001 (AOE-2001). Bound. Layer Meteor., 117, 5-36, https://doi.org/10.1007/s10546-0045641-8.

— C. Leck, P. O. G. Persson, M. L. Jensen, S. P. Oncley, and A. Targino, 2004: Experimental equipment: A supplement to the summertime Arctic atmosphere: Meteorological measurements during the Arctic Ocean Experiment 2001. Bull. Amer. Meteor. Soc., 85, ES14-ES18, https://doi.org/ 10.1175/BAMS-85-9-Tjernstrom.

— , and Coauthors, 2012: Meteorological conditions in the Central Arctic summer during the arctic summer cloud ocean study (ASCOS). Atmos. Chem. Phys., 12, 6863-6889, https:// doi.org/10.5194/acp-12-6863-2012.

_ - and Coauthors, 2014: The Arctic Summer Cloud Ocean Study (ASCOS): Overview and experimental design. Atmos. Chem. Phys., 14, 2823-2869, https://doi.org/10.5194/acp-14-2823-2014.

_ , and Coauthors, 2015: Warm-air advection, air mass transformation and fog causes rapid ice melt. Geophys. Res. Lett., 42, 5594-5602, https://doi.org/10.1002/2015GL064373.

Turner, D. D., S. A. Clough, J. C. Liljegren, E. E. Clothiaux, K. E. Cady-Pereira, and K. L. Gaustad, 2007: Retrieving liquid 
water path and precipitable water vapor from the Atmospheric Radiation Measurement (ARM) microwave radiometers. IEEE Trans. Geosci. Remote Sens., 45, 3680-3690, https://doi.org/10.1109/TGRS.2007.903703.

Uttal, T., and Coauthors, 2002: Surface Heat Budget of the Arctic Ocean. Bull. Amer. Meteor. Soc., 83, 255-276, https://doi.org/ 10.1175/1520-0477(2002)083<0255:SHBOTA > 2.3.CO;2.

Vihma, T., and Coauthors, 2014: Advances in understanding and parameterization of small-scale physical processes in the marine Arctic climate system: A review. Atmos. Chem. Phys., 14, 9403-9450, https://doi.org/10.5194/ acp-14-9403-2014.
Westwater, E. R., Y. Han, M. D. Shupe, and S. Y. Matrosov, 2001: Analysis of integrated cloud liquid and precipitable water vapor retrivals from microwave radiometers during SHEBA. J. Geophys. Res., 106, 32 019-32 030, https://doi.org/10.1029/ 2000JD000055.

Woods, C., R. Caballero, and G. Svensson, 2013: Large-scale circulation associated with moisture intrusions into the Arctic during winter. Geophys. Res. Lett., 40, 4717-4721, https://doi.org/10.1002/grl.50912. - , and —, 2017: Representation of arctic moist intrusions in CMIP5 models and implications for winter climate biases. J. Climate, 30, 4083-4102, https://doi.org/10.1175/ JCLI-D-16-0710.1. 